\title{
Plant-bacterium interactions analyzed by proteomics
}

\author{
Amber Afroz ${ }^{1 *}$, Muzna Zahur ${ }^{1}$, Nadia Zeeshan ${ }^{1}$ and Setsuko Komatsu ${ }^{2 *}$ \\ ${ }^{1}$ Department of Biochemistry and Molecular Biology, Nawaz Sharif Medical College, University of Gujrat, Hafiz Hayat Campus Gujrat, Gujrat, Pakistan \\ ${ }^{2}$ National Institute of Crop Science, National Agriculture and Food Research Organization, Tsukuba, Japan
}

Edited by:

Pingfang Yang, Chinese Academy of

Sciences, China

Reviewed by:

Christian Lindermayr, Helmholtz

Zentrum München - German

Research Center for Environmental

Health, Germany

Guozheng Qin, Chinese Academy of

Sciences, China

\section{*Correspondence:}

Amber Afroz, Department of Biochemistry and Molecular Biology, Nawaz Sharif Medical College, University of Gujrat, Hafiz Hayat Campus Gujrat, Gujrat, Pakistan. e-mail: ambernics01@gmail.com

Setsuko Komatsu, National Institute of Crop Science, National Agriculture and Food Research Organization, 2-1-18 Kannondai, Tsukuba 305-8518, Japan. e-mail: skomatsu@affrc.go.jp
The evolution of the plant immune response has resulted in a highly effective defense system that is able to resist potential attack by microbial pathogens. The primary immune response is referred to as pathogen associated molecular pattern (PAMP) triggered immunity and has evolved to recognize common features of microbial pathogens. In response to the delivery of pathogen effector proteins, plants acquired $\mathrm{R}$ proteins to fight against pathogen attack. R-dependent defense response is important in understanding the biochemical and cellular mechanisms and underlying these interactions will enable molecular and transgenic approaches for crops with increased biotic resistance. Proteomic analyses are particularly useful for understanding the mechanisms of host plant against the pathogen attack. Recent advances in the field of proteome analyses have initiated a new research area, i.e., the analysis of more complex microbial communities and their interaction with plant. Such areas hold great potential to elucidate, not only the interactions between bacteria and their host plants, but also of bacteria-bacteria interactions between different bacterial taxa, symbiotic, pathogenic bacteria, and commensal bacteria. During biotic stress, plant hormonal signaling pathways prioritizes defense over other cellular functions. Some plant pathogens take advantage of hormone dependent regulatory system by mimicking hormones that interfere with host immune responses to promote virulence (vir). In this review, it is discussed the cross talk that plays important role in response to pathogens attack with different infection strategies using proteomic approaches.

Keywords: pathogen associated molecular patter, pattern recognition receptors, effector triggered immunity, virulence, pathogenic bacteria, symbiotic bacteria, proteomics

\section{INTRODUCTION}

Unlike plant and animal cells, most bacteria are exposed to a constantly changing physical and chemical environment. Phylogenetic diversity of plant-associated bacteria (PAB) can categorize them in to commensals (acquire nutrients from the plant without damaging), mutualists (positively influence plant health), and pathogens (damage plant) (Newton et al., 2010). Notably pathogenic, commensals, or mutualists bacteria have developed strategies to interact with plants overlap, exceptionally modified physiology that accounts for individual need (Martin et al., 2003; Boller and Felix, 2009). Bacteria react to changes in their environment through changes in patterns of structural

\footnotetext{
Abbreviations: PAMP, pathogen associated molecular pattern; PRRs, pattern recognition receptors; PAB, plant-associated bacteria; ETI, effector triggered immunity; R, resistance proteins; HR, hypersensitive response; EF, Elongation factor; T2SSs, T3SSs, T4SSs, T6SSs, type 2,3,4,6 secretion systems; LRR, leucinerich repeat; EFR, elongation factor receptor; FLS2, flagellin sensing 2; vir, virulence; SA, salicylic acid; JA, jasmonic acid; MAP, mitogen-activated protein; 2-DE, two-dimensional polyacrylamide gel electrophoresis; MS, mass spectrometry; MALDI-TOF, matrix-assisted laser desorption/ionization time of flight; LC, liquid chromatography; MS/MS, tandom mass spectrometry; SOD, superoxide dismutase; ROS, reactive oxygen species; hrp, hypersensitive reaction and pathogenicity gene; $\mathrm{RuBisCO}$, ribulose-1, 5-bisphosphate carboxylase/oxygenase; PR, pathogenesis-related; GST, glutathione S-transferase; Hcp, hemolysin- coregulated proteins; OMVs, outer membrane vesicles; CPLL, hexapeptide ligand libraries.
}

proteins, transport proteins, toxins, and enzymes, which adapt them to a particular habitat (Boller and Felix, 2009). Enzymes are either constitutive in nature (always produced by cells independently of the composition of the medium) or inducible (produced in cells in response to the end product of a pathway). Regulation of enzyme activity which is mainly operates to regulate biosynthetic pathways and catabolites repression is considered a form of positive control because it affects an increase in rates of transcription of proteins (Deutscher, 2008).

Plant immunity that recognize pathogens by membrane proteins is termed as pattern recognition receptors (PRRs), which recognize pathogen associated molecular pattern (PAMP) and is basis of plant innate immunity (Gomez-Gomez and Boller, 2000). PAMP recognition also results in plant systemic acquired resistance and production of resistance $(\mathrm{R})$ proteins leading to effector triggered immunity (ETI), which is often accompanied by the hypersensitive response (HR), and programmed cell death (Jones and Dangl, 2006). Over the past 10 years, many R genes have been isolated that confer resistance to various pathogens including virus, bacteria, fungi, or nematodes (Martin et al., 2003). Based on predicted protein sequences, these $\mathrm{R}$ gene products are divided into intracellular protein kinases (Pto), proteins with an extracellular leucine-rich repeat (LRR) domain and a cytoplasmic protein kinase region (e.g., Xa21), intracellular proteins containing a region of a LRRs and a nucleotide binding site (RPS2, 
RPM1), intracellular proteins containing a region of homology to the Toll/IL-1R proteins in addition to LRRs and a nucleotide binding site (e.g., N, L6, RPP5), and proteins with LRRs that appear to encode membrane-bound extracellular proteins (e.g., Cf-4, Cf-9) (Chisholm et al., 2006; Zhang et al., 2012).

Proteomic analyses have made possible the analysis of complex microbial communities, which had great potential to elucidate not only the interactions between bacteria and their host plants, but also of bacteria-bacteria interactions. Proteomic reference data sets were established for various $\mathrm{PAB}$, via two-dimensional polyacrylamide gel electrophoresis (2-DE) gels, resulting in a few hundred identified proteins (Rosen et al., 2004; Chung et al., 2007), or multidimensional liquid chromatography-tandom mass spectrometry (LC-MS/MS) techniques resulting in the detection of more than 1000 proteins (Anderson et al., 2006; Bosch et al., 2008). Era is followed by gel free proteomics but quantitation procedures have to be optimized before the gel-based proteomics can be replaced by gel free procedures (Washburn et al., 2001).

Complete genome sequence of a Xylella fastidiosa is available which can be very helpful in genomics and proteomic studies of plant-bacterium interactions (Simpson et al., 2000; Bagnarol et al., 2007). More genomic data is needed for pathogenic and symbiotic bacteria to understand the molecular signaling pathways involved in plant-bacterium interactions. P. syringae and Xanthomonas campestris are important $\mathrm{PAB}$ on the grounds of agricultural importance and intensity of scientific research. Both are pathogenic on the model plant Arabidopsis (Jones et al., 2006a; Andrade et al., 2008). Pathogenic and mutualist PAB had been extensively studied (Rosen et al., 2004; Jacobs et al., 2012). The process of mutualism involved the significant change in the metabolism of both the mutualists and host, which involves a change in plant cell metabolism to support ATP synthesis and nitrogen fixation by the mutualist for nodule development (Delmotte et al., 2010). Transcriptomics data shows that pathogenic bacteria involve the hypersensitive reaction and pathogenicity (hrp) gene and different secretion systems (SS) for colonization and damaging host cells (Buttner and Bonas, 2010). In these review proteins of PAB bacteria have been compared. They typically exchange signals with their hosts and possess a range of specific adaptations for plant colonization. The importance of proteomics is explored to understand the molecular mechanism, by which bacteria adapt to live in association with plants for evolution of symbiosis and pathogenesis. This will opens up new research areas concerning protein-based plantmicrobe communication and provides important information regarding the manipulation of gene expression of specific proteins with the purpose of modifying plant behavior related to compatible or incompatible interactions.

\section{PAMP RECOGNITION BY PATTERN RECOGNITION RECEPTORS}

PAMPs constitute the first layer of plant innate immunity, and lacking of its recognition can lead to enhanced disease susceptibility. PAMPs are ideal elicitors for "non-self" surveillance systems such as chitin, ergosterol, and transglutaminase from fungi, and/or lipopolysaccharides and flagellin from bacteria, stimulate plant encoded PAMP receptors (Chisholm et al.,
2006). Intracellular responses associated with PAMP-triggered immunity (PTI) including rapid ion fluxes across the plasma membrane, mitogen-activated protein (MAP) kinase activation, production of reactive oxygen species (ROS), and rapid changes in gene expression and cell wall reinforcement. Suppression of PTI may be achieved by secretion of virulence (vir) effectors by the pathogens or by suppression of plant signaling. ETI is accompanied by production of $\mathrm{R}$ protein or HR, illustrating the dynamic co evolution between plants and pathogens (Jones and Dangl, 2006).

Flagellin, elongation factor (EF) Tu, peptidoglycan, lipopolysaccharide, and bacterial cold shock proteins are important PAMPS and plant responses induced by them are referred to as "basal" defenses (Newton et al., 2010). Upon recognition of highly conserved amino terminus of flagellin (flg22), flagellin sensing 2 (FLS2) induces a suite of defense responses, including MAP kinase signaling, transcriptional activation, and deposition of callose, a putative physical barrier at the site of infection (Gomez-Gomez et al., 1999). EF Tu potent bacterial PAMP in Arabidopsis and other members of the Brassicaceae family, serves as an adhesion factor at the bacterial surface, in addition to its primary role in translation (Boller and Felix, 2009). Asparate oxidase is required for PAMP-triggered RBOHD-dependent (responsible for stomatal closure) ROS burst and stomatal immunity against the $P$. syringae (Macho et al., 2012). The LRR receptor kinases, EF-Tu receptor and FLS2 are PRRs, contributing to disease resistance against the hemibiotrophic bacterium P. syringae (Roux et al., 2011).

The plant hormones, salicylic acid (SA), jasmonic acid (JA) and ethylene, have emerged as key players in the signaling networks involved in plant immunity. Rhamnolipids are glycolipids produced by bacteria and are involved in surface motility and biofilm development and are considered as PAMPS. Ethylene is found to be involved in rhamnolipid-induced resistance to $H$. arabidopsidis and to $P$. syringae whereas JA is essential for the resistance to $B$. cinerea. SA participates in restriction of all bacterial and fungal pathogens, so involving in broadly rhamnolipid mediated immunity (Sanchez et al., 2012). PAMPS are sometimes succeeded and sometimes fails to induce PTI depending upon the type of compatible and non-compatible interactions. Flagellin is capable of suppressing HR via PTI induction during an incompatible interaction (Wei et al., 2012).

Type III secretion system (T3SSs) were essential components of two complex bacterial machineries: the flagellum, which drives cell motility and the non-flagellar T3SS (NF-T3SS), which delivers effectors into eukaryotic cells (Mudgett, 2005). P. syringae use T3SS to deliver up to 40 effector proteins into host cells, inhibiting basal host defense responses, such as HR (McCann and Guttman, 2008).

PAMP induced PTI serves as a primary plant defense response against microbial pathogens, with MAP kinase cascade downstream of PAMP receptors. LRR-RLKs including PSKR1 act as PTI against pathogenic bacteria, and plants expressing this gene show enhanced PAMP responses and less lesion formation after infection with the bacterial pathogen $P$. syringae via jasmonate signaling pathway (Mosher et al., 2013). Peptidoglycan, an important PAMP from Staphylococcus aureus results in PTI, such as 
medium alkalinization, elevation of cytoplasmic calcium concentrations, nitric oxide, and camalexin production, and the post-translational induction of MAP kinase activities (Gust et al., 2007).

PAMP recognition also results in plant systemic acquired resistance and production of R proteins such as SUMM2 that becomes active when the MAP kinase cascade is disrupted by pathogens, leading to ETI (Zhang et al., 2012). In rice, the LRR-RK Xa21 confers resistance to Xanthomonas oryzae pv. oryzae strains carrying the Avr gene AvrXa21 (Song et al., 1995). AvrXa21 as a type I secreted sulfated peptide, is conserved among all Xanthomonas strains sequenced (P. Ronald, pers. communication), suggesting that AvrXa21/Xa21 constitutes a PAMP/PRR perception system (Lee et al., 2008). Although many PAMPs recognized by plants have been described, number of known PRR and PTI is still in its infancy, constituting a highly active and competitive field of research.

\section{PROTEOME ANALYSES OF PLANT ASSOCIATED BACTERIA}

$\mathrm{PAB}$ either they are pathogenic or symbiotic bacteria adhere to plant surfaces, invade the intercellular space of the host tissue, counteract plant defense systems and acquire nutrients. However either there is establishment of a pathogenic interaction or mutualist relationship develops. Cell surface proteins such as adhesions, polysaccharides, lipopolysaccharides, and degradative enzymes enable the degradation of the plant cell wall and also result in basal plant defenses (Newton et al., 2010). Proteins of $\mathrm{PAB}$ are studied either in planta, by means of bacterial responses to selected biomolecule or plant extracts, synthetic media, or secretome analysis to study the vir factor of the bacterial pathogens (Guerreiro et al., 1997; Corbett et al., 2005; Gourion et al., 2006; Chung et al., 2007). All studies had helped to study plant-microbe interactions.

$X$. fastidiosa, whose genome was fully sequenced leads to a clearer understanding of the biology of phytopathogenic organism at both the genomic and proteome levels (Simpson et al., 2000). The cellular and secreted protein profiling of pathogenic bacteria $X$. fastidiosa, led to the identification of proteins involved in cellular adhesion systems, proteases, antioxidant, and toxins (Smolka et al., 2003). These proteins can be the candidates for understanding of molecular mechanism of disease cycle of citrus variegated chlorosis and Pierce's disease in grapevine caused by $X$. fastidiosa. In non-virulent strain of E. chrysanthemi (opg mutant), differential expression of protein is not restricted to the envelope, but affects general metabolism such as membrane lipid composition, protein folding, carbohydrate catabolism, and protein degradation (Bouchart et al., 2007). The secretome of $X$. campestris pv. campestris using 2-DE and matrix-assisted laser desorption/ionization time of flight (MALDI-TOF) MS resulted in the identification of 87 proteins known to be involved in degradative activities and important for the infection of susceptible plant hosts (Watt et al., 2005).

Diverse pathogenic responses are reported due to differences in induction of vir between closely related strains. Chung et al. (2007) reported that degradative enzymes and virulent secreted proteins were only seen in the pathogenic $X$. campestris. Moreover, HtrA was identified in the virulent $X$. campestris pv. campestris strain (Chung et al., 2007). Unique proteins involved in T3SSs activities and iron uptake were only consistently expressed in the virulent strain of $P$. stewartii (Bouchart et al., 2007; Wu et al., 2007). Proteins accumulated in T3SS cascade were related to iron uptake, motility, adhesion, metabolism, and transcriptional regulation (Wu et al., 2007). The siderophorebased iron uptake system is a common mechanism employed by gram-negative pathogenic bacteria.

Bacteria are known to react to a number of signaling molecules released by plants by specific gene expression. In Rhizobium leguminosarum, the proteins of cells were analyzed in the presence and absence of 7, 40-dihydroxyflavone. Proteins related to amino acid metabolism and transport, flagellin, energy, translation and structure were induced (Guerreiro et al., 1997; Table 1). In Agrobacterium tumefaciens acetosyringone is sensed by the virA/G two component systems and induces expression of the vir genes encoded on the $\mathrm{Ti}$ plasmid (McCullen and Binns, 2006). Vir proteins were reported to have T4SSs for the delivery of bacterial T-DNA into the host cell and to have molecular chaperone functions as an assembly factor (McCann and Guttman, 2008; Lai et al., 2006). Incubation of A. tumefaciens in the presence of cut root material led to the induction of ribosomal protein, stress related chaperones, $\mathrm{ABC}$ transporters and sugar binding proteins indicating the significance of protein modifications in the interactions of Agrobacteria with plants (Rosen et al., 2003). Addition of suberin to Streptomyces scabies induced 17 proteins linked to primary, secondary metabolism and stress related pathway (Lauzier et al., 2008). Expression of superoxide dismutase (SOD) was enhanced in Frankia strains and Streptomyces coelicolor with plant extracts (Langlois et al., 2003; Bagnarol et al., 2007). Addition of carbohydrates such as rhamnose and ferulic acid to medium induce plant phenolic compound (rhamno galacturonate lyase and esterase) in D. dadantii (Kazemi-Pour et al., 2004). Other identified proteins of E. chrysanthemi were cellulase, flagellin, pectinases, endopectate lyases, pectin acetylesterases, pectin methylesterase, and polygalacturonase (Kazemi-Pour et al., 2004). Proteins involved in signal transduction, translation, ribosomal proteins and biogenesis, inorganic ion, lipid, amino acid, energy, transport, and metabolism were induced by plant extracts (Langlois et al., 2003). These results suggest that root exudates provide additional carbon sources to the bacteria and that physiological adaptation are required for efficient bacterial growth in the presence of plants. Differential proteins involved in carbohydrates, lipids, purines, metabolism, transcription, coenzymes, chaperones and iron transport regulation, essential for nitrogen fixation, seem to be strain dependent (Dixon and Kahn, 2004).

Proteome analysis is very tricky when dealing with separation of bacteria from infected plants and additional steps are needed to avoid the changes in proteome map. Protocols had been proposed for the bacterial separation by density gradient centrifugation using percoll or sucrose gradients (Gourion et al., 2006; Nomura et al., 2010). Jacobs et al. (2012) discussed the transcriptomics profile of $R$. solanacearum in vitro and he discussed the importance of T3SS in vir cascade of Ralsotonia ( $45 \%$ regulated by $\mathrm{HR}$ and Hrp gene). Proteome analysis of pathogenic bacteria $X$. campestris pv. campestris in 
Table 1 | Expression profiling of bacterial strains in differential medias/plant associated bacteria as pathogens, symbiotic or epiphytes.

\begin{tabular}{|c|c|c|c|c|c|}
\hline Organism & Pathogen & $\begin{array}{l}\text { Proteomic } \\
\text { techniques }\end{array}$ & No. of IP ${ }^{1}$ & $\begin{array}{l}\text { Virulence factor, secretion systems, } \\
\text { proteins expressed in vivo or under defined } \\
\text { medias in different bacteria }\end{array}$ & References \\
\hline $\begin{array}{l}\text { Xanthomonas } \\
\text { campestris pv. } \\
\text { Campestris/parasite }\end{array}$ & $\begin{array}{l}\text { Brassica oleracea, } \\
\text { (cv. Coracao de boi) } \\
\text { 4-6 days after } \\
\text { inoculation (DAl) }\end{array}$ & $\begin{array}{l}\text { 2-DE, } \\
\text { MALDI-TOF/TOF }\end{array}$ & 21 & $\begin{array}{l}\text { Proteins from young leaves of susceptible } \\
\text { Brassica cv infiltrated with } X \text {. campestris: } \\
\text { aspartate semialdehyde dehydrogenase, } \\
\text { elongation factor thermo unstable, } \\
\text { phosphomannose isomerase, adenine } \\
\text { triphosphate (ATP) synthase, ribosomal } \\
\text { protein, chaperonin, phosphoglycerate kinase, } \\
\text { and ATPase. }\end{array}$ & $\begin{array}{l}\text { Andrade et al., } \\
2008\end{array}$ \\
\hline
\end{tabular}

\begin{tabular}{lll}
\hline Frankia sp. Strains & Morella cerifera and & 2-DE, \\
M16467/symbiont & Myrica gale & MALDI-TOF MS
\end{tabular}

50
and ATPase.

With and without M. cerifera, M. gale seed

Bagnarol et al., increased abundance: signal transduction mechanisms, translation, ribosomal structure and biogenesis, chaperone heat shock protein, translation, amino acid and lipid transport, and metabolism. Thirty proteins with decreased abundance: Post-translational modification, chaperones, replication, transcription, translation, recombination, repair, energy production, conversion, lipid, inorganic ion, coenzyme, nucleotide, carbohydrate and secondary metabolite (transport and metabolism), cell wall biogenesis, and defense.

\begin{tabular}{llll}
\hline Pseudomonas & Olea europaea & 2-DE, & 7 \\
savastanoi pv. & subsp. europaea & MALDI-TOF MS & \\
savastanoi/6 weeks & cvs Galega and & \\
after infection & Cordovil de Serpa & \\
& &
\end{tabular}

\begin{tabular}{lll}
\hline X. campestris pv. & X. campestris pv. & 2-DE, \\
campestris strain & campestris strain & MALDI-TOD MS \\
& $11 \mathrm{~A} / 17$
\end{tabular}

Proteins accumulated in vivo in O. europaea
stems after infection by $P$. savastanoi:
aconitate hydratase, tellurium resistance 2009 protein, enolase, hypothetical protein, and calcium dependent protein kinase.

$\begin{array}{ll}\text { General protein accumulation in X. campestris: } & \text { Chung et al., } \\ \text { energy, metabolism, carbohydrate, lipid, } & 2007\end{array}$

energy, metabolism, carbohydrate, lipid, 2007 protein and cofactors and vitamins
metabolism, biosynthesis of secondary metabolites, transcription, translation, replication and repair, membrane transport, signal transduction, cell motility (22 higly abundant proteins of virulent vs. avirulent: aspartate semialdehyde dehydrogenase, cold shock protein, elongation factor, cellulase, L-isoaspartate protein carboxyl methyltransferase, malate dehydrogenase, $50 \mathrm{~S}$ ribosomal protein, fumaryl acetoacetate hydrolase, peptidyl-prolyl cis-trans isomerase, 10 kDa chaperonin).

\begin{tabular}{|c|c|c|c|c|c|}
\hline $\begin{array}{l}\text { Bradyrhizobium } \\
\text { Japonicum/Symbiont }\end{array}$ & Glycine max/21 DAl & $\begin{array}{l}\text { LCMS/MS, } \\
\text { LTQ-Orbitrap MS }\end{array}$ & $\begin{array}{l}3587 \\
\text { genes/proteins }\end{array}$ & $\begin{array}{l}\text { Proteins involved in translation, post } \\
\text { transcriptional regulation, nitrogenase } \\
\text { complex, aspartate amino transferase, carbon } \\
\text { metabolism, translation, and nucleic acid } \\
\text { metabolism. }\end{array}$ & $\begin{array}{l}\text { Delmotte } \\
\text { et al., } 2010\end{array}$ \\
\hline S. scabies & $\begin{array}{l}\text { Wild type/tatC } \\
\text { mutant strains }\end{array}$ & $\begin{array}{l}\text { 2-DE, } \\
\text { MALDI-TOF TOF } \\
\text { MS }\end{array}$ & 73 & $\begin{array}{l}\text { Tat dep virulence (vir) factors: glycosyl } \\
\text { hydrolase domain, putative alpha-L-fucosidase, } \\
\text { ABC-type } \mathrm{Fe}^{3+} \text { transport system, periplasmic } \\
\text { component, glycosyl hydrolase domain, } \\
\text { hydrolase of the } \alpha / \beta \text { superfamily, lipoprotein, }\end{array}$ & $\begin{array}{l}\text { Joshi et al., } \\
2010\end{array}$ \\
\hline
\end{tabular}


Table 1 | Continued

\begin{tabular}{lll}
\hline Organism & Pathogen & $\begin{array}{l}\text { Proteomic } \\
\text { techniques }\end{array}$
\end{tabular}$\quad$ No. of IP ${ }^{1}$

\section{Virulence factor, secretion systems, proteins expressed in vivo or under defined medias in different bacteria}

\begin{tabular}{|c|c|c|}
\hline $\begin{array}{l}\text { Sinorhizobium } \\
\text { meliloti/Symbiont }\end{array}$ & $\begin{array}{l}\text { Medicago truncatula } \\
\text { and Melilotus alba }\end{array}$ & $\begin{array}{l}\text { 2-DE, } \\
\text { MALDI-TOF MS }\end{array}$ \\
\hline
\end{tabular}

spermidine/putrescine transporter peptidebinding protein, and rhamnosidase.

binding protein, and rhamnosidase.

meliloti/Symbiont S. meliloti in vitro: transport proteins (ABC
Proteomes of the nodule bacteria compared to transporters, leucine and Iron binding protein), vitamin synthesis, stress-related processes, superoxide dismutase, betaine aldehyde dehydrogenase, heat shock protein, energy, GTP-binding proteins, oxidoreductase NAD protein, catalase, cell division, ribosomal protein, deoxyribonucleic acid transcription, translation, and central metabolism.

\begin{tabular}{lll}
\hline $\begin{array}{ll}\text { Methylobacterium } \\
\text { extorquens/epiphyte }\end{array}$ & A. thaliana & 2-DE, LC \\
& MS/MS & 45
\end{tabular}

45

$\begin{array}{ll}\text { PhytR regulated proteins: alcohol } & \text { Gourion et al., } \\ \text { dehydrogenase, catalase, reactive oxygen } & 2006\end{array}$

species, stress proteins, lactoylglutathione lyase, dioxygenase, glutathione-dependent formaldehyde dehydrogenase, malyl lyase, malate dehydrogenase, glutathione-dependent formaldehyde dehydrogenase, haloacetate dehalogenase, transcription elongation factor, lipid metabolism, propionyl-CoA carboxylase, and dehydrogenases reductases.

\begin{tabular}{|c|c|c|c|}
\hline $\begin{array}{l}\text { Rhizobium. } \\
R . \text { leguminosarum } \\
\text { bv. trifolii strain } \\
\text { ANU843/symbiont }\end{array}$ & $\begin{array}{l}\text { flavonoid } 7,4 \\
\text { dihydroxyflavone } \\
\text { (released due to } \\
\text { legume nodulation) }\end{array}$ & $\begin{array}{l}\text { 2-DE, Protein } \\
\text { sequencer }\end{array}$ & 12 \\
\hline $\begin{array}{l}\text { Azoarcus sp. strain } \\
\mathrm{BH} 72 / \text { endophyte }\end{array}$ & $\begin{array}{l}\text { PilR mutant } \\
\text { (necessary for } \\
\text { endophytic growth) }\end{array}$ & $\begin{array}{l}\text { 2-DE, } \\
\text { MALDI-TOF } \\
\text { MS/MS, } \\
\text { LC-MS/MS }\end{array}$ & $\begin{array}{l}785 / 30 \\
\text { abundant }\end{array}$ \\
\hline
\end{tabular}

R. leguminosarum grown in presence and
absence of 7,4-dihydroxyflavone: amino acid
metabolism and transport, flagellin, protein
translation and structure, energy, DnaK, NodE,
and NodB.

PilR mutant proteins: amino acid and energy metabolism, chaperones, iron metabolism and storage, ATP synthase, ABC transporter, heat shock protein, pyridoxal phosphate, DNA, RNA polymerase, S-adenosyl-L-homocysteine hydrolase, fumarate hydratase, and ATP-dependent protease.

\begin{tabular}{llll}
\hline $\begin{array}{l}\text { Burkholderia glumae } \\
\text { (grain and seedling }\end{array}$ & $\begin{array}{l}\text { Under hrpB } \\
\text { expression (induced } \\
\text { rot in rice, bacterial }\end{array}$ & $\begin{array}{l}\text { 2-DE, } \\
\text { ESter attack to plant) }\end{array}$ & $\begin{array}{l}34 \\
\text { secretory/12 } \\
\text { cytoplasmic }\end{array}$
\end{tabular}

wilt in many crops)

\author{
Induction of type III secretion system (T3SS), Kang et al., \\ acetylglutamate kinase, ribosomal protein, 2008 \\ transcription elongation factor, Acetyl-CoA \\ biotin carboxyl carrier protein, chaperone \\ protein DnaK, lipoprotein, ATP synthase, \\ phenylalanyl-tRNA synthase, and alkyl \\ hydroperoxide reductase.
}

\begin{tabular}{|c|c|c|c|c|}
\hline $\begin{array}{l}\text { Rhizobium } \\
\text { leguminosarum } \\
\text { Biovar viciae } \\
\text { (symbiont) }\end{array}$ & $\begin{array}{l}\text { Pisum sativum and } \\
\text { Vicia cracca }\end{array}$ & Microarray & $\begin{array}{l}\text { Genes expressed related to tricarboxylic acid } \\
\text { cycle, Succinate, pyruvate/inositol catabolism, } \\
\alpha \text { aminobutyrate metabolism, regulators, } \\
\text { exported and cell surface molecules, multi } \\
\text { drug exporters, and heat and cold shock } \\
\text { proteins (early induced) fix genes, nif (late } \\
\text { induced). }\end{array}$ & $\begin{array}{l}\text { Karunakaran } \\
\text { et al., } 2009\end{array}$ \\
\hline $\begin{array}{l}\text { Erwinia } \\
\text { chrysanthemi } \\
\text { (soft rot) }\end{array}$ & $\begin{array}{l}\text { Chrysanthemum } \\
\text { leaves extract }\end{array}$ & $\begin{array}{l}\text { 2-DE, } \\
\text { MALDI-TOF MS }\end{array}$ & $\begin{array}{l}\text { Endopectate lyases, pectin acetyl esterases, } \\
\text { pectin methylesterase, poly galacturonase, } \\
\text { flagellin, and elongation factor. }\end{array}$ & $\begin{array}{l}\text { Kazemi-Pour } \\
\text { et al., } 2004\end{array}$ \\
\hline
\end{tabular}




\section{Table 1 | Continued}

\begin{tabular}{|c|c|c|c|c|c|}
\hline Organism & Pathogen & $\begin{array}{l}\text { Proteomic } \\
\text { techniques }\end{array}$ & No. of IP 1 & $\begin{array}{l}\text { Virulence factor, secretion systems, } \\
\text { proteins expressed in vivo or under defined } \\
\text { medias in different bacteria }\end{array}$ & References \\
\hline $\begin{array}{l}\text { Agrobacterium } \\
\text { tumefaciens }\end{array}$ & $\begin{array}{l}200 \mu \mathrm{M} \\
\text { acetosyringone (As) }\end{array}$ & $\begin{array}{l}\text { 2-DE, } \\
\text { MALDI-Q-TOF } \\
\text { MS }\end{array}$ & 11 & $\begin{array}{l}\text { As induced vir proteins, type IV secretion } \\
\text { system (T4SS), newly As-induced proteins } \\
\text { regulated by the virA/virG, an unknown protein } \\
\text { Y4mC, and heat shock protein. }\end{array}$ & Lai et al., 2006 \\
\hline $\begin{array}{l}\text { Streptomyces } \\
\text { coelicolor }\end{array}$ & Lemna minor fronds & $\begin{array}{l}\text { 2-DE, } \\
\text { MALDI-TOF MS }\end{array}$ & 31 & $\begin{array}{l}\text { Differential proteins of } S \text {. coelicolor with and } \\
\text { without } L \text {. minor fronds in minimal medium: } \\
\text { proteins related to energy, metabolism, protein } \\
\text { synthesis, proteins involved in the acquisition } \\
\text { of carbon, stress-induced (chaperonin, } \\
\text { ATP-GTP binding protein, tellurite resistance } \\
\text { protein, and Fe superoxide dismutase). }\end{array}$ & $\begin{array}{l}\text { Langlois et al., } \\
2003\end{array}$ \\
\hline
\end{tabular}

\begin{tabular}{lll}
\hline S. meliloti strain 2011 & Medicago & LC MS/MS \\
& $\begin{array}{l}\text { truncatula/3-6 D for } \\
\text { drought }\end{array}$ &
\end{tabular}

Proteins accumulated in M. truncatula in vivo with S. meliloti under drought: protein synthesis/degradation, stress proteins, RNA regulation, secondary metabolism, signaling, amino acid carbohydrate, nucleic acid/hormone metabolism, glycolysis/tricarboxylic acid cycle.

\begin{tabular}{|c|c|c|c|c|c|}
\hline $\begin{array}{l}\text { Streptomyces } \\
\text { scabies }\end{array}$ & $\begin{array}{l}\text { potato suberin, } \\
\text { lipidic plant polymer }\end{array}$ & $\begin{array}{l}\text { 2-DE, Protein } \\
\text { sequencer } \\
\text { MS/MS }\end{array}$ & 19 & $\begin{array}{l}\text { Differential proteins in } S \text {. scabies in minimal } \\
\text { media with and without } 0.2 \% \text { potato suberin: } \\
\text { proteins with increased abundance in } \\
\text { response to suberin (Nucleotide and amino } \\
\text { acid metabolism, glycolysis/tricarboxylic acid } \\
\text { cycle enzymes, chaperonin, } \\
\text { phenylacetaldehyde dehydrogenase, } \\
\text { fructose-bisphosphate aldolase, triose } \\
\text { phosphate isomerase, ABC transporter, } \\
\text { ATPase subunit, lipoprotein, and serine } \\
\text { hydroxymethyl transferase). }\end{array}$ & $\begin{array}{l}\text { Lauzier et al., } \\
2008\end{array}$ \\
\hline
\end{tabular}

\begin{tabular}{|c|c|c|c|c|c|}
\hline $\begin{array}{l}\text { Frankia sp. strain } \\
\text { Ccl3 (Symbiont) }\end{array}$ & $\begin{array}{l}\text { Casuarina } \\
\text { cunninghamiana } \\
\text { and C. glauca/Alnus } \\
\text { incana and } \\
\text { Elaeagnus } \\
\text { angustifolia }\end{array}$ & $\begin{array}{l}\text { 2-DE, MS/MS, } \\
\text { LC MS/MS }\end{array}$ & $73 / 53$ & $\begin{array}{l}\text { Frankia strains in root nodules of Alnus incana } \\
\text { and Elaeagnus angustifolia (cell wall/growth } \\
\text { enzymes, solute-binding proteins (amino acids, } \\
\text { peptides, inorganic ions) (ABC transporter, } \\
\text { molybdate binding proteins, } \\
\text { Leu/lleNal/Glu/Thr-binding protein precursor, } \\
\text { hydrolytic enzymes, proteins involved in cell } \\
\text { processes (DNA polymerase, signal } \\
\text { transduction histidine, and T2SS protein). }\end{array}$ & $\begin{array}{l}\text { Mastronunzio } \\
\text { et al., } 2009\end{array}$ \\
\hline $\begin{array}{l}\text { Pectobacterium } \\
\text { atrosepticum } \\
\text { (Pathogen in potato) }\end{array}$ & $\begin{array}{l}\text { Potato stem/tubers } \\
\text { extract }\end{array}$ & $\begin{array}{l}\text { 2-DE, } \\
\text { MALDI-TOF MS }\end{array}$ & 40 & $\begin{array}{l}\text { Abundant proteins in minimal medium with } \\
\text { potato tuber extracts: (T3SS protein, pectin } \\
\text { enzymes, vir protein Svx, flagellar hook } \\
\text { associated protein, endo-polygalacturonase, } \\
\text { dihydrolipoamide dehydrogenase, } \\
\text { hexosaminidase, pectate lyase, fructose } \\
\text { bisphosphate aldolase, ABC transporter, } \\
\text { glyceraldehyde 3-phosphate dehydrogenase, } \\
\text { and chaperones). }\end{array}$ & $\begin{array}{l}\text { Mattinen et al., } \\
2007\end{array}$ \\
\hline $\begin{array}{l}\text { Ralstonia } \\
\text { solanacearum } \\
\text { UW551 (phylotype II) } \\
\text { and GMI1000 }\end{array}$ & $\begin{array}{l}\text { S. lycopersicum cv. } \\
\text { Bonny Best }\end{array}$ & Microarray & 109 by HrpB & $\begin{array}{l}\text { Enhancement of hrpB regulated genes via } \\
\text { T3SS, sucrose uptake and catabolism via SCR } \\
\text { ABC, sucrose dependent phosphoenol } \\
\text { pyruvate-carbohydrate phosphotransferase, } \\
\text { glycolysis enzymes, cell wall-degrading }\end{array}$ & $\begin{array}{l}\text { Jacobs et al., } \\
2012\end{array}$ \\
\hline
\end{tabular}

Larrainzar et al., 2007 
Table 1 | Continued

\begin{tabular}{|c|c|c|c|c|}
\hline Organism & Pathogen & $\begin{array}{l}\text { Proteomic } \\
\text { techniques }\end{array}$ & No. of IP 1 & $\begin{array}{l}\text { Virulence factor, secretion systems, } \\
\text { proteins expressed in vivo or under defined } \\
\text { medias in different bacteria }\end{array}$ \\
\hline
\end{tabular}

enzymes, exopolysaccharide, reactive oxygen species, inorganic, organic and aminoacid and nucleic acid metabolic enzymes, tricarboxylic acid cycle intermediates, and pentose phosphate pathway.

\begin{tabular}{lll}
\hline B. japonicum & G. max L. Merrill & 2-DE, \\
USDA110 (Symbiont) & cultivar Akishirome. & MALDI-TOF MS \\
& 7-49 DAl
\end{tabular}
Proteins accumulation related to transcription, Nomura et al., Nif and Fix proteins, translation, protein 2010 folding, and degradation, synthetic enzyme of the poly-beta-hydroxybutyrate, solute transporter, and elongation factor-thermo unstable.

\begin{tabular}{lll}
\hline A. tumefaciens. C58 & Solanum & 2-DE, \\
strain ATCC 33970 & lycopersicum cv. & MALDI-TOF MS \\
& Rutgers stem, roots &
\end{tabular}
Augmentation of $\mathrm{ABC}$ transporter, ATPase Rosen et al., protein, alcohol dehydrogenase, enoyl CoA 2003 hydratase/isomerase, aldehyde dehydrogenase, protein-L-isoaspartate O-methyltransferase, acetyl COA carboxylase, ribosomal proteins (chaperonin, hydrolases, and sugar-binding protein), and aldolase.

\begin{tabular}{lll}
\hline B. japonicum & HM medium (Cole & 2-DE, \\
USDA110 & MALDI-TOF MS \\
& 1973)/root nodule \\
& residing \\
& B. japonicum
\end{tabular}

Suppression of fatty acid, nucleic acid and cell surface synthesis, DNA metabolism-related proteins and proteolytic enzymes.

Enhancement of translation, transcription related proteins, elongation factor, chaperones (heat shock protein, chaperonin), ATP synthase, DNA polymerase, and nitrogen metabolism proteins.

\begin{tabular}{lll}
\hline B. japonicum & G. max. cv. Williams & 2-DE, \\
USDA110 & 82. Nodule protein & MALDI-TOF MS
\end{tabular}

(S)

$\begin{array}{ll}\begin{array}{l}\text { Augmentation of proteins related to nitrogen, } \\ \text { carbon metabolism, protein synthesis, }\end{array} & \text { Emerich, } 2005 \\ \text { scaffolding and degradation, cellular } & \end{array}$
scaffolding and degradation, cellular
detoxification function (ATP synthetase,
elongation factor ribosomal protein, chaperonin, heat shock protein), stress regulation, signaling communication. Decline of fatty acid and nucleic acid metabolism, solute transport (ABC transporter) proteins, protein synthesis, scaffolding and degradation, cellular detoxification, stress regulation and signaling communication.

\begin{tabular}{|c|c|c|c|c|c|}
\hline B. japonicum & $\begin{array}{l}\text { G. max, Vigna } \\
\text { unguiculata and } \\
\text { Macroptilium } \\
\text { atropurpureum }\end{array}$ & LC-MS/MS & 2000 & $\begin{array}{l}\text { Accumulation of housekeeping proteins, } \\
\text { ribosomal proteins, ABC-type transporter } \\
\text { sulfonate-binding protein, enoyl-CoA } \\
\text { hydratase, transketolase, } \\
\text { hydroxyphenylpyruvate dioxygenase, } \\
\text { nitropropane dioxygenase. }\end{array}$ & $\begin{array}{l}\text { Koch et al., } \\
2010\end{array}$ \\
\hline $\begin{array}{l}\text { Xylella fastidiosa } \\
\text { strain } 9 a 5 c\end{array}$ & $\begin{array}{l}\text { Brazilian sweet } \\
\text { orange }\end{array}$ & $\begin{array}{l}\text { 2-DE, } \\
\text { MALDI-TOF MS }\end{array}$ & 30 & $\begin{array}{l}\text { Synthesis of aconitate hydratase, DNAk } \\
\text { protein, dihydrolipoamide dehydrogenase, } \\
\text { lipase/esterase, 30S, 50S ribosomal protein, } \\
\text { inosine-5'-monophosphate dehydrogenase, } \\
\text { heat shock protein, peptidyl-prolyl cis-trans } \\
\text { isomerase, ATP synthase, } \\
\text { aspartate-B-semialdehyde dehydrogenase, }\end{array}$ & $\begin{array}{l}\text { Smolka et al., } \\
2003\end{array}$ \\
\hline
\end{tabular}


Table 1 | Continued

\begin{tabular}{|c|c|c|c|c|}
\hline Organism & Pathogen & $\begin{array}{l}\text { Proteomic } \\
\text { techniques }\end{array}$ & No. of IP' & $\begin{array}{l}\text { Virulence factor, secretion systems, } \\
\text { proteins expressed in vivo or under defined } \\
\text { medias in different bacteria }\end{array}$ \\
\hline
\end{tabular}

References edias in different bacteria

alcohol dehydrogenase, fructose-bisphosphate aldolase, malate dehydrogenase, ABC transporter ATP-binding protein, chaperone, elongation factor, and RNA polymerase.

\begin{tabular}{|c|c|c|c|c|c|}
\hline $\begin{array}{l}\text { Xanthomonas citri } \\
\text { subsp. citri }\end{array}$ & $\begin{array}{l}\text { TSE medium (with } \\
\text { sucrose and } \\
\text { glutamic acid) } \\
\text { induce } \\
\text { pathogenesity }\end{array}$ & $\begin{array}{l}\text { 2-DE, LC } \\
\text { MS/MS }\end{array}$ & 1702 & $\begin{array}{l}\text { Expression of Hrp gene dependent T3SS } \\
\text { enzymes, tricarboxylic acid cycle, } \\
\text { glycolysis/gluconeogenesis, pentose } \\
\text { phosphate pathway, other sugar metabolism, } \\
\text { urea cycle, pyrimidine and purine biosynthesis, } \\
\text { fatty acid synthesis and degradation pathways, } \\
\text { polyamine biosynthesis, DNA, RNA, protein } \\
\text { metabolism, initiation, elongation, } \\
\text { transcription, translation factors, cell structure } \\
\text { and function, division, transport, pathogenesis } \\
\text { and vir. }\end{array}$ & $\begin{array}{l}\text { Soares et al., } \\
2010\end{array}$ \\
\hline
\end{tabular}

\begin{tabular}{|c|c|c|c|c|}
\hline $\begin{array}{l}\text { X. campestris pv. } \\
\text { campestris } \mathrm{B} 100\end{array}$ & $\begin{array}{l}\text { 2-DE, } \\
\text { MALDI-TOF MS }\end{array}$ & 87 & $\begin{array}{l}\text { Accumulation of outer membrane proteins } \\
\text { with signal peptide, ATP synthase beta chain, } \\
\text { 30s ribosomal protein, metabolic proteins, } \\
\text { protein maintenance and folding (chaperonin, } \\
\text { DNA k), and degradive enzymes (cellulase, } \\
\text { lipase). }\end{array}$ & $\begin{array}{l}\text { Watt et al., } \\
2005\end{array}$ \\
\hline
\end{tabular}

\begin{tabular}{|c|c|c|c|c|c|}
\hline $\begin{array}{l}\text { Pantoea stewartii } \\
\text { subsp. stewartii } \\
\text { (Pnss) vir/P. stewartii } \\
\text { subsp. indologenes } \\
\text { (Pnsi) avir }\end{array}$ & $\begin{array}{l}\text { Stewart's bacterial } \\
\text { wilt and leaf blight } \\
\text { of maize and sweet } \\
\text { corn }\end{array}$ & $\begin{array}{l}\text { 2-DE, LC } \\
\text { MS/MS, } \\
\text { MALDI-TOF MS }\end{array}$ & 21 & $\begin{array}{l}\text { Proteins accumulation in virulent verses } \\
\text { avirulent strain: siderophore-based iron uptake } \\
\text { system, motility, adhesion, and biofilm } \\
\text { formation (flagellin B homolog), pilus adhesion, } \\
\text { transdolase, secretory protein (T3SS protein, } \\
\text { HrcJ, } 60 \text { kDa chaperonin), mannosyl } \\
\text { transferase, transdolase, LysR, transcriptional } \\
\text { activator belonging to the AraC family, ABC } \\
\text { transporter. }\end{array}$ & Wu et al., 2007 \\
\hline
\end{tabular}

\begin{tabular}{|c|c|c|c|c|c|}
\hline A. tumefaciens & & LC MS/MS & 12 & $\begin{array}{l}\text { Enhancement of T4SS secretome proteins, } \\
\text { virB, hemolysin- coregulated protein, } \\
\text { periplasmic binding protein, amino acid-binding } \\
\text { periplasmic protein, hemin-binding lipoprotein, } \\
\text { and dipeptide protein. }\end{array}$ & Wu et al., 2008 \\
\hline $\begin{array}{l}\text { S. meliloti mutants } \\
2011-3.4 \text { and } \\
1021 \Delta \mathrm{hfq}\end{array}$ & Alfalfa & $\begin{array}{l}\text { 2-DE, } \\
\text { MALDI-TOF MS }\end{array}$ & 33 & $\begin{array}{l}\text { Proteins lower in abundance were sugar } \\
\text { transporters, enzymes of central carbon } \\
\text { metabolism, glycine betaine, electron } \\
\text { transport chain, iron, sugar catabolism, } \\
\text { biosynthesis of aminoacids, vitamins, purines } \\
\text { and pyrimidines, chaperonin, heat shock } \\
\text { protein, and ABC transporter. Proteins } \\
\text { augmented were metabolism of nitrogen } \\
\text { sources (mainly amino acids), glycine cleavage } \\
\text { system, metabolic enzymes such as ornithine } \\
\text { cyclodeaminase, arginase, } \\
\text { adenosylhomocysteinase, and phosphoenol } \\
\text { pyruvate carboxykinase. }\end{array}$ & $\begin{array}{l}\text { Torres- } \\
\text { Quesada et al., } \\
2010\end{array}$ \\
\hline
\end{tabular}

${ }^{1}$ IP: Number of identified protein.

Abbreviations: DAl, days after inoculation; ATP, adenine triphosphate; As, Acetosyringone; vir, virulence; T3SS, Type III secretion system; T4SS, Type IV secretion system; 2-DE, two-dimensional polyacrylamide gel electrophoresis; MS, Mass spectrometry; MS/MS, Tandom Mass spectrometry; MALDI-TOF, Matrix-assisted laser desorption/ionization time of flight; LC, liquid chromatography. 
association with B. oleracea and Pseudomonas savastanoi pv. savastanoi resulted in comprehensive expression analysis including stress and metabolic proteins (Andrade et al., 2008; Campos et al., 2009). Increased levels of proteins involved in xanthan biosynthesis, stress response, and the metabolism were induced in $X$. campestris in planta conditions compared with in vitro grown cells (Andrade et al., 2008). Chaperonin is reported to be involved in stress responses and EF, which acts as an important PTI in the plants, is the key component of the translational machinery of bacteria. Xanthan is an extracellular polysaccharide probably responsible for disease symptom in planta growth via mucoid appearance of the bacterial colonies and wilting of host plants by blocking the water flow in xylem vessels (Buttner and Bonas, 2010).

The differential proteome analysis of in planta and in vitro grown cells of Methylobacterium extorquens resulted in the identification of 45 metabolic proteins and proteins involved in stress response such as the extracellular protease, SOD, catalases, and the DNA protection protein (Gourion et al., 2006). The protein analysis of cyanobacteria living in symbiosis revealed several adaptations to a symbiotic lifestyle, including an increase in proteins involved in energy production and nitrogen fixation. On the other hand, proteins involved in photosynthesis were decreased, pointing toward a heterotrophic lifestyle under symbiotic conditions (Dixon and Kahn, 2004). The general proteome analysis of bacteroids is compared with in vitro grown cells in order to identify nodule specific adaptations, over time or when plants were exposed to drought stress (Delmotte et al., 2010; Nomura et al., 2010). ABC-type transporters was present in nodule bacteria for transport of amino acids and inorganic ions along with proteins involved in vitamin synthesis, fatty acid, nucleic acid, cell surface synthesis, and stress-related processes (Sarma and Emerich, 2006). Integrated proteomics and transcriptomics data for B. japonicum bacteroids resulted in 2315 proteins involved in carbon and nitrogen metabolism, including a complete set of tricarboxylic acid cycle enzymes, gluconeogenesis and pentose phosphate pathway enzymes, along with other proteins important in symbiosis. Amino acids (Asn, Gln, Pro), organic acids (threonic acid), sugars (Rib, maltose), and polyols (mannitol) were reported to be more abundant in symbiotic roots (Delmotte et al., 2010). In planta studies is very effective to study the interactions between plant and bacteria.

\section{GENE REGULATION IN SYMBIOTIC BACTERIA}

An effective nitrogen-fixing symbiosis establishes as a result of a complex molecular interplay between both partners that involves bacteria-plant signal exchanges and intricate signaling processes (Dixon and Kahn, 2004). Rhizobia start as epiphyte attaches to the root hair, penetrate through the epidermis, divide within the plant-derived infection thread and then invade the cortical cells. On the other hand, in response to the bacterial infection, the plant cortical cells form a new organ, the nodule, where the bacteria differentiate into bacteroids and commence nitrogen fixation. An increased abundance of proteins involved in protein synthesis and degradation was observed during the early stage of nodule development, which may be explained by a restructuring of the proteome to attain a symbiotic lifestyle. Transformation of a free-living bacterium to a nitrogen-fixing endosymbiont results in significant physiological and developmental changes in the rhizobia, including the expression of nif and fix genes, which encode the proteins involved in the nitrogen fixation process in later stages of infection (Karunakaran et al., 2009; Nomura et al., 2010). To withstand changing environmental conditions, the bacteria must possess the ability to undergo specialized physiological adaptations. These response mechanisms are complex and remain largely unexplored. Comparative proteomic display of methylobacterium grown in vitro and in planta leads to identification of metabolic proteins and proteins involved in stress response such as the extracellular protease HtrA, SOD, catalases, and the DNA protection protein. In this study, also a key regulator, PhyR, was identified and shown to be essential for phyllosphere colonization (Gourion et al., 2006). These proteins seem to be important for the symbiotic relationship of microbe with plant.

Proteomic and transcriptomics approach was used to identify genes whose expression is regulated by the NifA-RpoN system in Rhizobium etli in symbiosis with Phaseolus vulgaris (Salazar et al., 2010; Figure 1). Twenty four proteins associated with NifA and RpoN motifs were identified via differentially proteomic analysis of mutant and wild type $R$. etli strain CFN42. Transcriptomics analysis helps to identify proteins with isoelectric points or molecular weights outside the electrophoretic resolution range of the 2-DE. NifA is a regulator for nitrogen fixation genes in symbiotic diazotrophic bacteria, and controlled by the oxygen-responsive two-component FixL-FixJ/Redox-sensing system RegS-RegR (Dixon and Kahn, 2004). Two further studies support regulatory role of $\mathrm{Hfq}$ in symbiosis process in S. meliloti (Barra-Bily et al., 2010; Torres-Quesada et al., 2010). Hfq is suspected to contribute to control central metabolic pathways in free-living bacteria and affects survival and nitrogen fixation capacity of the symbionts in the nodules, probably via the regulation of nifA and fixK1/K2 (Torres-Quesada et al., 2010). Barra-Bily et al. (2010) found that oxidative stress proteins and proteins involved in RpoE regulation were down regulated in hfq mutant. High expression of TonB-dependent receptors involved in transport processes of various carbohydrates was reported in Sphingomonas (Delmotte et al., 2009).

Hauberg et al. (2010) reported the PilR regulated cascade differentially present in symbiont Azoarcus sp. strain BH72 as compared to its mutant. It may be explained by a restructuring of the proteome to attain a symbiotic lifestyle. Koch et al. (2010) discussed host adaptation of B. japonicum in nodules of soybean, cowpea or siratro. Transcriptomics and proteomics analyses resulted in the identification of seven unique gene products that were the house keeping gens, along with $\mathrm{ABC}$ transporter, substrate-binding protein and a monooxygenase. In planta studies impart PhyR regulation along with the role of T3SS in infection process. The infection process resulted in augmentation of enzymes involved in gluconeogenesis, glycolysis, pentose pathway, amino acid, nucleic acid, lipid metabolism along with stress related proteins.

Protein secretion of a symbiont (Sinorhizobium meliloti) and a pathogen ( $P$. syringae DC3000) in the presence of root exudates from $A$. thaliana and Medicago sativa was studied. SOD is 


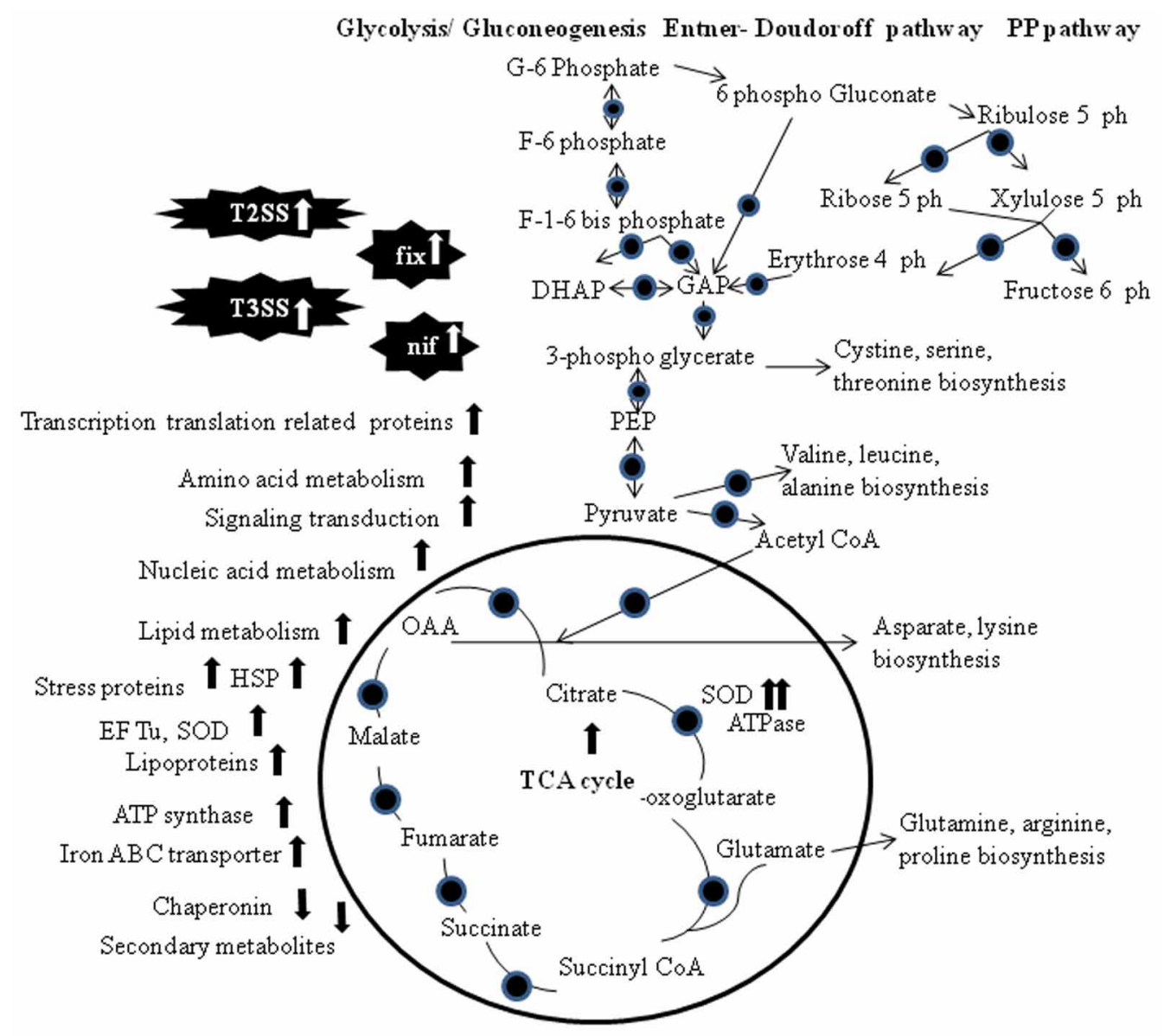

FIGURE 1 | Visualization of metabolic and proteomics pathways that may supply symbionts with energy under symbiotic conditions. The TCA cycle, gluconeogenesis/glycolysis, Entner-Doudoroff pathway and the Pentose Phosphate pathway are shown. Circles indicate proteins that have been detected at the transcriptomics and/or proteomics level. Abbreviations:
PP, Pentose Phosphate; DHAP, dihydroxyacetone phosphate; GAP, glyceraldehyde-3-phosphate; PEP, phosphoenolpyruvate; OAA, oxaloacetate; G, glucose; F, fructose; EF-Tu, elongation factor thermo unstable; SOD, superoxide dismutase; HSP, heat shock protein; T2SS, type II secretion system; T3SS, type III secretion system. known to be necessary for symbiotic properties in S. meliloti and had higher expression in interaction with M. sativa (De-la-Pena et al., 2008). Extracellular proteins of the nitrogen-fixing symbiont Frankia were analyzed by dissecting nodules of infected cortical cells (Mastronunzio et al., 2009). The secreted proteins within the pool of identified proteins were recognized based on their export signal peptides by in silico prediction. Proteins detected in the secretome of three different Frankia strains were mainly solute-binding proteins, underlining the importance to acquire nutrients during symbiosis.

\section{VIRULENCE FACTORS AND SECRETIONS SYSTEMS (SS) INVOLVED IN PLANT INFECTION}

The genes encoding vir and symbiosis determinants are carefully regulated in order to prevent dissipative or premature expression. The expression of these genes is regulated by transcriptional regulators, which are part of regulatory systems such as the quorum sensing system and respond to different extracellular stimuli for instance, nutrients, oxygen levels, presence of plant-derived molecules or population density (Buttner and Bonas, 2010). The concerted action of different regulatory systems can vary substantially, even between closely related strains (Seo et al., 2008). A major task in understanding the regulation of gene expression is the identification of genes that are under the control of distinct regulators. Usually, transcriptomics studies are performed to address this question; however, proteomic analyses are also used, in particular when the aim is the evaluation of the impact on secreted proteins.

The establishment of a symbiotic or pathogenic association is largely dependent on the interaction between the microorganism and the host plant via secreted proteins. Effector proteins secreted by the pathogenic bacteria, either into the extracellular milieu or directly into the host cell cytosol target the host. The proposed biological roles and the mode of action of various effectors in plant pathogenicity have been reviewed (Mudgett, 2005). Combination of SS is involved in process of pathogenesis. In Xanthomonas spp six types of protein SS (I-VI) are involved in pathogenesis process (Bonemann et al., 2010). Effector proteins 
interfere with the signaling cascades of susceptible hosts to counteract, for the plant innate immune responses, which are triggered by PAMPs (Mudgett, 2005). Proteomic studies were frequently applied to analyze the spectrum of proteins secreted by a particular system or to identify the system by which a certain protein is transferred.

The co-regulation of the synthesis of enzymes secreted via the T2SS and T3SS has been reported frequently (Figures 1, 2). One reasonable explanation for this co-regulation is based on the observation that substrates that are secreted via the T2SS are not only associated with bacterial vir but can also induce plant defense responses. The concurrent induction of the T2SS and the T3SS probably allows the pathogen to counteract basal plant defense responses that are elicited by proteins released via the T2SS with the effector proteins transported by the T3SS (Jha et al., 2007). T3SS are used to inject different effector proteins, formerly known as avirulence proteins, directly into the host cell via an extracellular pilus that acts as channel (McCann and
Guttman, 2008). T3SS is required for pathogenicity in host plants and for eliciting a rapid hypersensitive resistance response in nonhost plants, and the genes encoding T3SS were named HR and pathogenicity (hrp) genes (Jacobs et al., 2012). hrp genes were identified in most Gram-negative plant pathogenic bacteria with the exception of A. tumefaciens and Xylella fastidiosa (Buttner and Bonas, 2010). Homologues of the hrp genes were also found in different rhizobia (Jones and Dangl, 2006). To identify the SS that is responsible for the transport of distinct vir factors, the secretome of a SS mutant strain and the wild-type strain is compared (Kazemi-Pour et al., 2004; Watt et al., 2009). Joshi et al. (2010) discussed twin arginine transport (Tat) dependent translocation of vir factor in S. scabies under T3SSs. Tat-secreted vir proteins includes lipoproteins, ABC transporters, phospholipases/phosphoesterases, $\beta$-lactamase, and proteins involved in Fe homeostasis and Tat dep vir factors (Table 1). T3SS-secreted proteins responsible for vir process usually silenced in plantpathogenic bacteria and were only induced during the plant

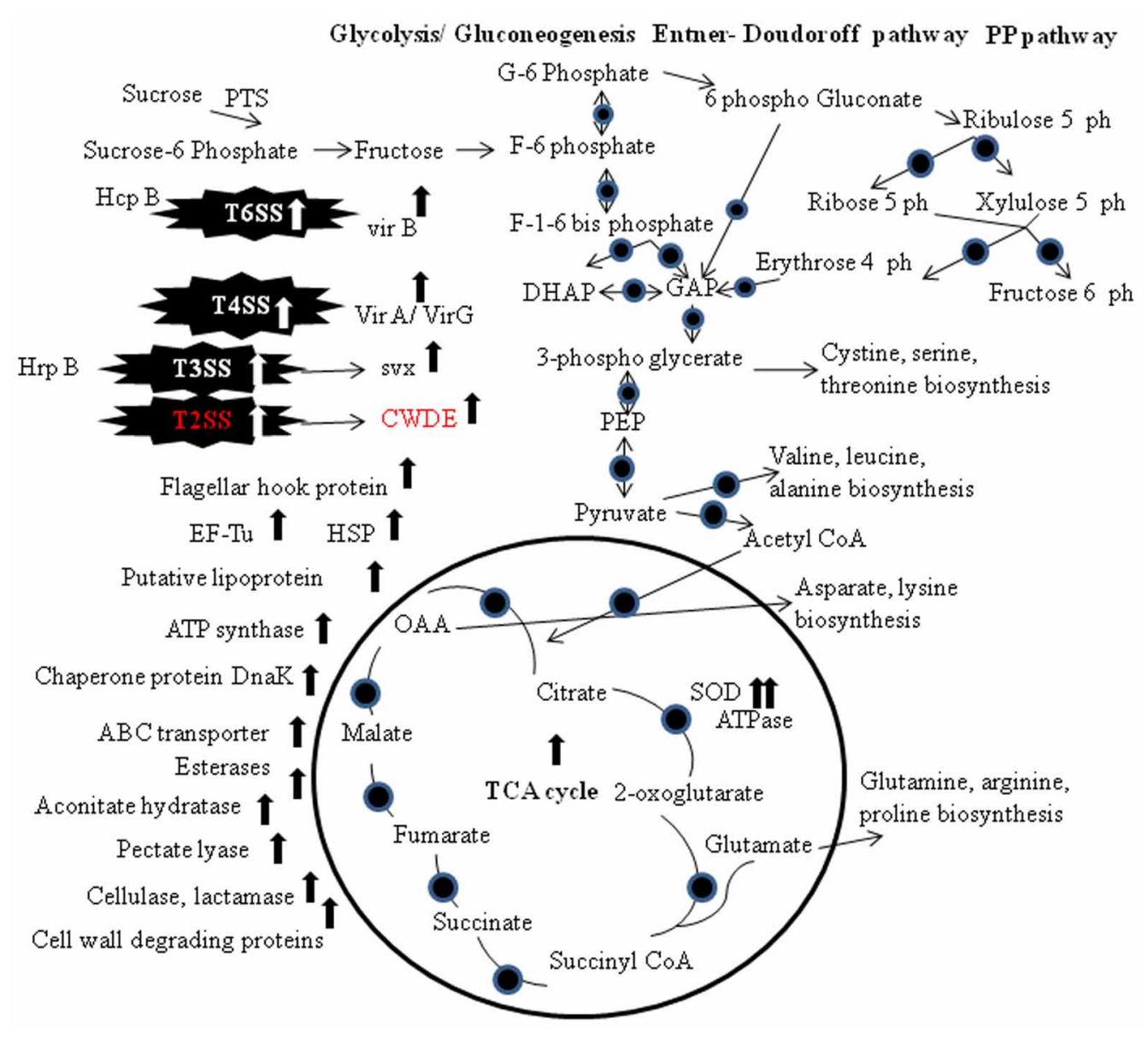

FIGURE 2 | Biochemical pathways of the pathogen secretion system and proteins expression. The TCA cycle, gluconeogenesis/glycolysis, Entner-Doudoroff pathway and the Pentose Phosphate pathway are shown. Circles indicate proteins that have been detected at the transcriptomics and/or proteomics level. Abbreviations: PP, Pentose Phosphate; PTS, phosphoenol pyruvate-carbohydrate phosphotransferase system; G, glucose; F, fructose; PEP, phosphoenol pyruvate; TCA, tricarboxylic acid; OAA, oxaloacetate; T6SS, type VI secretion system; T4SS, type IV secretion system; T3SS, type III secretion system; T2SS, type II secretion system; EF-Tu, elongation factor thermo unstable; SOD, superoxide dismutase; HSP, heat shock protein; CWDE, cell wall degrading enzymes. 
infection process (Buttner and Bonas, 2002). Another vir factor Svx (secreted vir factor from Xanthomonas), in a secrotomic study of $P$. atrosepticum, was analyzed (Corbett et al., 2005).

Addition of galacturonate, pectin or plant extract to the medium resulted in the induction of vir factors in Enterobacteriaceae (Kazemi-Pour et al., 2004; Mattinen et al., 2007). In Xanthomonas secretome studies a defined medium with fructose, sucrose and casamino acids was found to induce T3SS gene (Wengelnik et al., 1996; Yamazaki et al., 2008). To study the secretome of A. tumefaciens, acetosyringone was added to induce VirB1 (Wu et al., 2008). P. atrosepticum in the presence of potato tuber extract, induce vir factors such as pectic enzymes, proteinase, and the avirulence protein homolog Svx (Mattinen et al., 2007). Likewise, culturing X. campestris pv. campestris in the presence of $B$. oleracea led to the induction of a nuclease, a ribonuclease, peptidases, proteases and cell-wall-degrading enzymes (Watt et al., 2009). T3SS was induced by addition of flavonoid (genistein) to the medium, resulted in secretion of the nodule outer proteins (Nops), which is involved in the host-range determination (Jones and Dangl, 2006).

Protein secretion into the extracellular space or other space was mediated by outer membrane vesicles (OMVs) in some bacterial strains. OMVs are an ideal structure to transport hydrophobic compounds like membrane proteins into host cells or quorum signals to neighboring cells (Wai et al., 2003; Mashburn and Whiteley, 2005). OMVs of gram-negative bacteria contain outer membrane proteins, periplasmic proteins, lipopolysaccharides, phospholipids, DNA, toxins, and other factors associated with vir (Kadurugamuwa and Beveridge, 1997; Mashburn and Whiteley, 2005). They are known to be constantly liberated from the outer membrane and are thus a likely source of outer membrane proteins in the culture supernatant (Kadurugamuwa and Beveridge, 1997). In the presence of vir factor inducing medium, two major protein groups were detected: outer membrane proteins and vir -associated proteins. The latter group included proteins of the T3SS, effector proteins, two cell wall-degrading enzymes, a cellulase, and a xylosidase.

Several periplasmic proteins were detected in the OMVs, which may be entrapped in the vesicle lumen during their release from the outer membrane. One of the identified vir proteins is $\mathrm{HrpF}$, the putative translocon of the T3SS that is proposed to be inserted into the host membrane and serves as attachment site for the T3SS conduit. It is currently assumed that this protein is transported via the T3SS and then pushed into the host membrane (Buttner and Bonas, 2002). However, since OMVs of mammalian pathogens have been reported to deliver vir -factors into host membranes by fusion (Wai et al., 2003), it can be suspected that HrpF is inserted into the plant membrane by fusion of OMVs carrying HrpF.

Proteomic studies confirmed the transcriptional activation of vir factor (Hrp) via T2SS in Burkholderia glumae and X. axonopodis pv. citri (Kang et al., 2008; Yamazaki et al., 2008). Vir factor Svx was secreted via the T2SS in P. atrosepticum (Corbett et al., 2005). Protein secretion in the Gram-positive S. scabies via the twin arginine transport (Tat) pathway was analyzed. In Gram-negative bacteria the Tat system is part of the T2SS (Johnson et al., 2006). T2SS are present in many gram-negative proteobacteria, and toxins and extracellular enzymes such as proteases, lipases, and cell-wall-degrading enzymes were secreted via the T2SS (Jacobs et al., 2012). Components of the T2SS were identified as vir factors in the plant pathogenic bacteria D. dadantii, Pectobacterium carotovorum, Xanthomonas spp., and Ralstonia solanacearum (Buttner and Bonas, 2010). Comparison of the extracellular proteome of a tatC mutant and the wild type in combination with an in silico search for proteins harboring a secretion signal identified 73 predicted secretory proteins whose expression was reduced in the mutant. The tatC mutant strain was almost completely avirulent, indicating that the activity of this transport system is mandatory for vir. Hemolysin- coregulated proteins (Hcp) vir factor is structural component of a type T6SSs, components of the T4 bacteriophage tail tube and is required to puncture the host membrane in the context of phage infection (Bonemann et al., 2010). Hcp is transported via the T6SS in A. tumefaciens (Wu et al., 2008). Comparative proteome analysis with and without acetosyringone confirmed the induction of Vir proteins comprising the type IV secretion system for the delivery of bacterial T-DNA into the plant host cell. More induced proteins were identified, one of these is a molecular chaperone and functions as an assembly factor for the type IV secretion system (Lai et al., 2006; McCann and Guttman, 2008). The proteins that enable successful infection of plants are termed vir factors. These include cell surface proteins such as adhesins, polysaccharides, lipopolysaccharides, and degradative enzymes such as cellulases, pectate lyases, and proteases that enable the degradation of the plant cell wall under the action of T2SS (Jacobs et al., 2012; Figure 2).

\section{PROTEOMICS ANALYSIS OF THE PLANTS AFFECTED BY BACTERIA}

Inspite of lot of work on plant-microbe interactions, there are still lot of gaps in different proteomic studies of plants in response to bacterial infection. Here there is brief preview of some of research articles regarding plant responses to bacterial attack, which can be helpful to understand the plant microbe interactions (Table 2). Miao et al. (2008) reported that caffeoyl CoA 3-O-methyltransferase gene was down regulated in susceptible cultivars of tomato in response to inoculation with bacteria. Defense-related antioxidants such as pathogenesis-related (PR) -9 and metabolic enzymes were reported in A. thaliana in response to P. syringae (Jones et al., 2004, 2006a). Both of these groups of antioxidant enzymes were considered to have probable significant roles in the regulation of redox conditions within infected tissue. Many new techniques such as hexapeptide ligand libraries (CPLL such as proteominer) had been used to decrease the high abundant proteins for enrichment of low abundant protein. Frohlich et al. (2012) applied the CPLL in A. thaliana leaf proteins after infection with virulent $P$. syringae. 2-DE showed a decrease in high-abundance proteins and an enrichment of less abundant proteins in leaf samples. Mass spectrometric analyses of leaf extracts led to the identification of 312 bacterial proteins in infected Arabidopsis leaves.

Accumulation of free linolenic and benzoic acid or reduction in lauric acid was found to be important indicator of an 
Table 2 | Proteomics analysis of plants in response to pathogenic/symbiotic bacteria.

\begin{tabular}{|c|c|c|c|c|c|}
\hline Studied organism & Pathogen & $\begin{array}{l}\text { Proteomic } \\
\text { approach }\end{array}$ & No. of IP 1 & Identified proteins & References \\
\hline A. thaliana & P. syringae & 2-DE LC MS/MS & 52 & $\begin{array}{l}\text { Abundant proteins (defense-related, } \\
\text { Transcription, elongation factor, peroxiredoxin, } \\
\text { arginase, lipase/acylhydrolase, PS11, } \\
\text { sedoheptulose bisphosphatase, Protein folding } \\
\text { and turnover, cytochrome, Cellular transport } \\
\text { and ion homeostasis, decreased proteins, } \\
\text { metabolism, and proteasome. }\end{array}$ & $\begin{array}{l}\text { Jones et al., } \\
2006 a\end{array}$ \\
\hline A. thaliana & P. syringae & iTRAQ & 5 & $\begin{array}{l}\text { Phosphoproteome changes } 4 \text { proteins } \\
\text { (dehydrin, co-chaperone, heat shock protein, } \\
\text { plastid-associated protein) and ribulose-1, } \\
\text { 5-bisphosphate carboxylase/oxygenase large } \\
\text { subunit (RuBisCO LSU). }\end{array}$ & $\begin{array}{l}\text { Jones et al., } \\
2006 \mathrm{~b}\end{array}$ \\
\hline A. thaliana & P. syringae & $\begin{array}{l}\text { 2-DE; LC } \\
\text { MS/MS }\end{array}$ & 2 & Glutathione S-transferase (GST), peroxiredoxin. & $\begin{array}{l}\text { Jones et al., } \\
2004\end{array}$ \\
\hline $\begin{array}{l}\text { O. sativa transgenic } \\
\text { and/or inoculated } \\
\text { with Xanthomonas } \\
\text { oryzae pv. oryzae }\end{array}$ & X. oryzae pv. oryzae & $\begin{array}{l}\text { 2-DE MS/MS } \\
\text { Protein } \\
\text { sequencer }\end{array}$ & 10 & $\begin{array}{l}\text { Accumulation of pathogenesis-related protein } \\
\text { (PR) -5, superoxide dismutase, peroxiredoxin, } \\
\text { glycine cleavage H protein, glyceraldehydes } \\
\text { 3-phosphate dehydrogenase, triose phosphate } \\
\text { isomerase, oxygen evolving complex is } \\
\text { downregulated. }\end{array}$ & $\begin{array}{l}\text { Mahmood } \\
\text { et al., } 2006\end{array}$ \\
\hline O. sativa & X. oryzae pv. oryzae & 2-DE, MS/MS & 20 & $\begin{array}{l}\text { Defense-related plasma membrane proteins } \\
\text { with increased abundance are ATPase, } \\
\text { phosphatase, hypersensitive response, } \\
\text { prohibitin, zinc finger and } \mathrm{C}_{2} \text { domain protein, } \\
\text { universal stress protein, heat shock protein, } \\
\text { ascorbate peroxidase (APX), alcohol } \\
\text { dehydrogenase, and quinone reductase. }\end{array}$ & $\begin{array}{l}\text { Chen et al., } \\
2007\end{array}$ \\
\hline
\end{tabular}

\begin{tabular}{lll}
\hline O. sativa & $\begin{array}{l}\text { X. campestris pv. } \\
\text { Oryzicola }\end{array}$ & $\begin{array}{l}\text { 2-DE, } \\
\text { MALDI-TOF MS }\end{array}$ \\
& & $\begin{array}{l}\text { PR-1, PR-10, receptor-type protein kinase, } \\
\text { ascorbate peroxidase, adenine triphosphate } \\
\text { (ATP) synthase, RuBisCO LSU, ribonuclease, } \\
\text { phospholipase, and GTP binding protein. }\end{array}$ \\
\hline
\end{tabular}

\begin{tabular}{|c|c|c|c|c|c|}
\hline L. hirsutum (leaflets) & $\begin{array}{l}\text { Cl. michiganensis } \\
\text { ssp. michiganensis }\end{array}$ & $\begin{array}{l}\text { 2-DE, ESI-MS } \\
\text { /MS }\end{array}$ & 47 & $\begin{array}{l}\text { Regulatory proteins accumulated: defense and } \\
\text { stress related (PR-3, GST, APX, superoxide }\end{array}$ & $\begin{array}{l}\text { Coaker et al., } \\
2004\end{array}$ \\
\hline
\end{tabular}

dismutase), regulatory proteins, protein synthesis and processing (chaperonin, elongation factor-thermo unstable), carbon metabolism: RuBisCO (LSU, small subunit, activase, epimerase, triose phosphate isomerase), metabolism [glycine cleavage system, oxygen evolving enhancer (OEE)], and ATP production [nucleotide diphosphate kinase (NDK), ATP synthase].

\begin{tabular}{|c|c|c|c|c|c|}
\hline M. truncatula, root & S. meliloti & 2-DE, PMF & 99 & $\begin{array}{l}\text { Proteins increased in abundance: defense and } \\
\text { stress related (PR-9, -10, APX, superoxide } \\
\text { dismutase), S-adenosyl methionine synthase, } \\
\text { GST, elongation factor, NDK, protein disulfide } \\
\text { isomerase (PDI), OEE, protein synthesis and } \\
\text { degradation, isoflavone reductase, hormone } \\
\text { dependent proteins, and metabolic proteins } \\
\text { (ATP synthase, fructose bisphosphate } \\
\text { aldolase). }\end{array}$ & $\begin{array}{l}\text { Mathesius } \\
\text { et al., } 2003\end{array}$ \\
\hline
\end{tabular}


Table 2 | Continued

\begin{tabular}{|c|c|c|c|c|c|}
\hline Studied organism & Pathogen & $\begin{array}{l}\text { Proteomic } \\
\text { approach }\end{array}$ & No. of IP 1 & Identified proteins & References \\
\hline S. lycopersicum & P. solanacearum & $\begin{array}{l}\text { Protein } \\
\text { sequencer }\end{array}$ & 15 & $\begin{array}{l}\text { Proteins highly accumulated: protein } \\
\text { destination and storage ( } 60 \text { kDa chaperonin, } \\
\text { PDI, heat shock protein), protein synthesis, } \\
\text { metabolism (RuBisCO activase, plastocyanin, } \\
\text { glycine dehydrogenase, OEE), and defense } \\
\text { (calgranulin, AMA). }\end{array}$ & $\begin{array}{l}\text { Afroz et al., } \\
2009\end{array}$ \\
\hline Rice (var. Co43) & $\begin{array}{l}\text { P. fluorescens } \mathrm{KH}-1 \\
\text { (PGPR) }\end{array}$ & $\begin{array}{l}\text { 2-DE, MS, LC } \\
\text { MS/MS }\end{array}$ & 23 & $\begin{array}{l}\text { Highly abundant proteins of energy } \\
\text { metabolism, photosynthesis, protein } \\
\text { degradation and antioxidation: GST, NDK, } \\
\text { chaperone, thioredoxin, RuBisCO LSU, and } \\
\text { proteosome }\end{array}$ & $\begin{array}{l}\text { Kandasamy } \\
\text { et al., } 2009\end{array}$ \\
\hline $\begin{array}{l}\text { Malus Domestica cv. } \\
\text { Holsteiner Cox }\end{array}$ & P. fluorescens & $\begin{array}{l}\text { SDS-PAGE, } \\
\text { MS/MS }\end{array}$ & 5 & $\begin{array}{l}\text { PR-2, }-3,-4 b,-5,-10 \text {, ribonuclease-like, } \\
\text { endochitinase class III. }\end{array}$ & $\begin{array}{l}\text { Kurkcuoglu } \\
\text { et al., } 2004\end{array}$ \\
\hline S. lycopersicum & P. solanacearum & $\begin{array}{l}\text { Protein } \\
\text { sequencer }\end{array}$ & 15 & $\begin{array}{l}\text { Proteins with increased accumulation in } \\
\text { response to JA and SA: defense (S-adenosyl } \\
\text { methionine synthase, arginase, peroxiredoxin, } \\
\text { threonine diaminase, polyphenol oxidase, } \\
\text { leucine aminopeptidase), protein synthesis } \\
\text { (PDI), protein destination and storage (60 kDa } \\
\text { chaperonin), energy (glycine cleavage, ATP } \\
\text { synthase), and RuBisCO LSU downregulated. }\end{array}$ & $\begin{array}{l}\text { Afroz et al., } \\
2009\end{array}$ \\
\hline G. $\max$ & $\begin{array}{l}\text { B. japonicum } \\
\text { (symbiotic root } \\
\text { nodules) }\end{array}$ & $\begin{array}{l}\text { GC MS, } \\
\text { LC-QTOF-MS }\end{array}$ & 166 & $\begin{array}{l}\text { Genes highly expressed: fatty acid, amino acid, } \\
\text { carboxylic acid metabolism, disaccharides, } \\
\text { isoflavonoids, and glucosinolate. }\end{array}$ & $\begin{array}{l}\text { Brechenmacher } \\
\text { et al., } 2010\end{array}$ \\
\hline
\end{tabular}

1 IP: Number of identified protein.

Abbreviations: ATP, adenine triphosphate; GST, glutathione S-transferase; RuBisCO, ribulose-1, 5-bisphosphate carboxylase/oxygenase; LSU, large subunit; APX, ascorbate peroxidase; PR, pathogenesis-related protein; OEE, oxygen evolving enhancer; PDI, protein disulfide isomerase; NDK, nucleotide diphosphate kinase; 2-DE, two-dimensional polyacrylamide gel electrophoresis; MS, Mass spectrometry; MS/MS, Tandom Mass spectrometry; LC, liquid chromatography; GC, gas chromatography; MALDI-TOF, Matrix-assisted laser desorption/ionization time of flight.

active plant defense response in G. max. $\gamma$-aminobutyric acid, proline, and glutamine reduction resulted in G. max susceptibility after Bradyrhizobium japonicum inoculation (Brechenmacher et al., 2010). Transcriptomic and proteomic approaches identified numerous genes and proteins involved in carbon and nitrogen metabolism, plant defense responses, nutrient exchange, and signal transduction that are significantly regulated in G. max colonized by B. japonicum (Brechenmacher et al., 2010). Li et al. (2012) discussed importance of PR-1 and PR-10 in rice defense against Xanthomonas campestris. Components of PSII, mitochondrial permeability transition and cytoplasmic antioxidant enzymes were modified during R-gene-mediated HR. PR-9 and PR-5 were induced in response to $X$. oryzae pv. Oryzae in rice (Mahmood et al., 2006). Analyses clearly revealed that four defense-related proteins (PR-5, Probenazole-inducible protein, SOD and peroxiredoxin) were induced for both compatible and incompatible $X$. oryzae pv. Oryzae races, where PR-5 and probenazole-inducible protein were more rapid and showed higher induction in incompatible interactions and in the presence of JA. Furthermore, the sense PR-5 transgenic rice plants were more resistant than the susceptible vector control against X. oryzae pv. Oryzae (Mahmood et al., 2009).
Chen et al. (2007) analyzed proteins from rice plasma membrane to study the early defense responses involved in Xa21 mediated resistance. $X a 21$ is a rice receptor kinase, which is predicted to perceive the $X$. oryzae pv. oryzae signal at the cell surface, leading to the "gene-for-gene" resistance response (Song et al., 1995). Twenty proteins that were differentially expressed had potential functions in rice defense. Proteins expressed in partially resistant lines and a susceptible tomato species that are regulated in response to $C$. michiganensis ssp. michiganensis were identified 72 and $144 \mathrm{~h}$ post inoculation. Using 2-DE and MS, 26 differentially regulated tomato proteins were identified; 12 of which were directly related to defense such as PR-3, PR-9, and stress responses (Coaker et al., 2004). PR proteins seem to be good candidates to develop the incompatible interactions with bacteria along with SAR in plants. Proteomic analysis was also used to detect the responses of the model legume $M$. truncatula to the pathogenic bacterium $P$. aeruginosa (Mathesius et al., 2003). There is accumulation of 154 proteins, among which 21 are related to defense and stress responses. Molecular chaperones, protein related to defense, destination and storage were differentially expressed in resistant tomato cvs (Afroz et al., 2009). Apical membrane antigen was found to be the novel protein 
expressed in susceptible cultivar in SA cascade (Afroz et al., 2010). Kandasamy et al. (2009) reported differential proteins in response to $P$. fluorescens in rice leaf sheath (Table 2). Along with protein degradation and antioxidation, photosynthetic proteins thioredoxin was upregulated. Defense proteins can be the other target protein for the disease resistance against bacterial pathogens. Tomato seed treatment with rhizobacteria $P$. fluorescens exhibited growth promotion along with protection from infection by Fusarium oxysporum (Ramamoorthy et al., 2002). PR-2, PR-3, and PR-5 were found to be induced in P. fluorescens treated plants challenged with F. oxysporum. Similarly, the expression of glutathione S-transferase (GST) is known to be involved in tagging toxic endogenous substrates with glutathione conjugation to transport toxic substrates into the vacuole through a glutathione pump (Ishikawa, 1992). GST is reported to be induced in response to $P$. syringae in Arabidopsis, and has an important role in plant defense from oxidative damages caused by various biotic or abiotic stresses such as heavy metal, wounding, ethylene, ozone, and pathogen attack (Marrs, 1996; Jones et al., 2004, 2006a,b).

Chloroplasts may be key players in plant defense, as the loss of integrity of PSII may lead to the HR-associated oxidative burst, thereby restricting pathogen growth. Proteins related to photosynthesis, defense, protein destination and storage had been down regulated in response to $P$. syringae infection in soybean (Zou et al., 2005). Proteins differentially expressed in response to $P$. savastanoi pv. savastanoi on O. europaea stems were related with photosynthesis and metabolism (Campos et al., 2009). Nonpathogenic bacteria ( $P$. putida) had been reported to promote systemic resistance in different host plants as well. Stimulation of antifungal material (phytoalexin) and proteins in lipoxygenase pathway in tomato were found after infection with $P$. putida (Akram et al., 2008).

Holzmeister et al. (2011) used 2-D fluorescence difference gel electrophoresis technology to demonstrate the role of niric oxide in plant defense signaling. After infection of wild type and Arabidopsis mutant strain, it was found that in the infection by avirulent $P$. syringae there is accumulation of defense, redox as well as stress proteins, while in virulent infection only defense proteins were expressed. This imparts importance of stress proteins in plant defense signaling. Induction of defense enzymes involved in phenyl propanoid pathway and accumulation of phenolics and PR-proteins might have contributed to restriction of invasion of F. oxysporum f. sp. lycopersici in tomato roots. Induction of defense proteins and chemicals in tomato by $P$. $f l u$ orescens isolate against $F$. oxysporum was studied. Defense-related proteins such as PR-9, PR-2, PR-5, and $46 \mathrm{kDa}$ chitinase increased in bacterized tomato root tissues (Ramamoorthy et al., 2002).

\section{REFERENCES}

Afroz, A., Khan, M. R., Ahsan, N., and Komatsu, S. (2009). Comparative proteomic analysis of bacterial wilt susceptible and resistant tomato cultivars. Peptides 30, 1600-1607.

Afroz, A., Khan, M. R., and Komatsu, S. (2010). Proteomic analysis of tomato cultivars treated with growth elicitor's jasmonic acid and salicylic acid. Protein Pept. Lett. 17, 836-846.

Akram, A., Ongena, M., Duby, F., Dommes, J., and Thonart, P. (2008). Systemic resistance and lipoxygenase-related defence response induced in tomato by Pseudomonas putida strain BTP1. BMC Plant Biol. 8:113. doi: 10.1186/1471-2229-8-113

Proteins related to photosynthesis, defense, destination, and storage are decreased as a result of bacterial infection followed by the induction of PR proteins in JA or SA pathway. Defense-related proteins, PR proteins and PSII destruction and repair system can be the candidates for improved resistance against bacterial infection in plants.

\section{CONCLUSIONS}

This review summarizes the use of proteomic approaches to understand the molecular and cellular processes that govern host responses such as PTI, PRR, and ETI. Detailed global comparison of response pathways using proteomics has allowed the identification of novel proteins whose biological role warrants in-depth biochemical and cellular elucidation. Finally understanding of biotic stress responses may identify promising novel targets for the development of cultivars with improved disease resistance. Various types of bacteria can trigger rapid responses in plant cell cultures and defense responses in intact plant tissues (Jones and Dangl, 2006). Flagellin and lipopolysaccharides have been identified as common bacterial determinants or PAMPs that act as elicitors of defense responses in plant cells (Felix et al., 1999). $\mathrm{R}$ genes that confer resistance to various phytopathogens are proposed to be part of a positive feedback loop to amplify the response triggered by PAMP perception. ETI is often accompanied by local cell death known as the HR illustrating the dynamic evolution between plants and pathogens (Martin et al., 2003; Jones and Dangl, 2006).

To fully elucidate microbial metabolism and its responses to environmental factors, it will be necessary to go beyond the information obtained from proteomic studies alone. There is need of integration of data resulting from the functional characterization and quantification of molecules representing from genes, transcripts and proteins to metabolites (Delmotte et al., 2010). First steps in this direction were made by setting up extensive proteomic reference databases and by compiling proteomic and transcriptomics data sets (Bosch et al., 2008; Koch et al., 2010). To profit from such analyses as best as possible, databases should be set up that combine and integrate the results obtained in different studies. With complete genome sequences of several host and pathogen partners now available, there are literally hundreds of candidate genes and proteins with potential applications in crop protection. Knowledge generated from research such as described in this special issue will open new avenues for the engineering of durable resistance to bacterial pathogens in plants. Identified proteins involved in plant tolerance to stresses could be used for development of disease resistant cultivars as well as these proteins can be used as markers for the identification of type of infection.

Anderson, D. C., Campbell, E. L., and Meeks, J. C. (2006). A soluble 3D LC/MS/MS proteome of the filamentous cyanobacterium Nostoc punctiforme. J. Proteome Res. 5, 3096-3104.

Andrade, A. E., Silva, L. P., Pereira, J. L., Noronha, E. F., Reis, F. B. Jr., Bloch, C. Jr., et al. (2008). In vivo proteome analysis of Xanthomonas campestris pv. campestris in the interaction with the host plant Brassica oleracea. FEMS Microbiol. Lett. 281, 167-174.

Bagnarol, Popovici, J., Alloisio, N., Marechal, J., Pujic, P., Normand, P., et al. (2007). Differential Frankia protein patterns induced by phenolic extracts from Myricaceae seeds. Physiol. Plant. 130, 380-390. 
Barra-Bily, L., Fontenelle, C., Jan, G., Flechard, M., Trautwetter, A., Pandey, S. P., et al. (2010). Proteomic alterations explain phenotypic changes in Sinorhizobium meliloti lacking the RNA chaperone Hfq. J. Bacteriol. 192, 1719-1729.

Boller, T., and Felix, G. (2009). A renaissance of elicitors: perception of microbe associated molecular patterns and danger signals by pattern-recognition receptors. Annu. Rev. Plant Biol. 60, 379-406.

Bonemann, G., Pietrosiuk, A., and Mogk, A. (2010). Tubules and donuts: a type VI secretion story. Mol. Microbiol. 76, 815-821.

Bosch, G., Skovran, E., Xia, Q., Wang, T., Taub, F., Miller, J. A., et al. (2008). Comprehensive proteomics of Methylobacterium extorquens AM1 metabolism under single carbon and non methylotrophic conditions. Proteomics 8, 3494-3505.

Bouchart, F., Delangle, A., Lemoine, J., Bohin, J. P., and Lacroix, J. M. (2007). Proteomic analysis of a non-virulent mutant of the phytopathogenic bacterium Erwinia chrysanthemi deficient in osmoregulated periplasmic glucans: change in protein expression is not restricted to the envelope, but affects general metabolism. Microbiology 153, 760-767.

Brechenmacher, L., Lei, Z., Libault, M., Findley, S., Sugawara, M., Sadowsky, M. J., et al. (2010). Soybean metabolites regulated in root hairs in response to the symbiotic bacterium Bradyrhizobium japonicum. Plant Physiol. 153, 1808-1822.

Buttner, D., and Bonas, U. (2002). Getting across bacterial type III effector proteins on their way to the plant cell. EMBO J. 21, 5313-5322.

Buttner, D., and Bonas, U. (2010). Regulation and secretion of Xanthomonas virulence factors. FEMS Microbiol. Rev. 34, 107-133.

Campos, A., da Costa, G., Coelho, A. V., and Fevereiro, P. (2009). Identification of bacterial protein markers and enolase as a plant response protein in the infection of Olea europaea subsp. europaea by Pseudomonas savastanoi pv. savastanoi. Eur. J. Plant Pathol. 125, 603-616.

Chen, F., Yuan, Y., Li, Q., and He, Z. (2007). Proteomic analysis of rice plasma membrane reveals proteins involved in early defense response to bacterial blight. Proteomics 7, 1529-1539.

Chisholm, S. T., Coaker, G., Day, B., and Staskawicz, B. J. (2006). Host microbe interactions: shaping the evolution of the plant immune response. Cell 124, 803-814.

Chung, W.-J., Shu, H.-Y., Lu, C.-Y., Wu, C.-Y., Tseng, Y.-H., Tsai, S.-F., et al. (2007). Qualitative and comparative proteomic analysis of Xanthomonas campestris pv. campestris 17. Proteomics 7, 2047-2058.

Coaker, G. L., Willard, B., Kinter, M., Stockinger, E. J., and Francis, D. M. (2004). Proteomic analysis of resistance mediated by $\mathrm{Rcm} 2.0$ and Rcm 5.1, two loci controlling resistance to bacterial canker of tomato. Mol. Plant Microbe Interact. 17, 1019-1028.

Cole, M. A., and Elkan, G. H. (1973). Transmissible resistance to penicillin G, neomycin, and chloramphenicol in Rhizobium japonicum. Antimicrob. Agents Chemother. 4, 248-253.

Corbett, M., Virtue, S., Bell, K., Birch, P., Burr, T., Hyman, L., et al. (2005). Identification of a new quorum-sensing-controlled virulence factor in Erwinia carotovora subsp. atroseptica secreted via the type II targeting pathway. Mol. Plant Microbe Interact. 18, 334-342.

De-la-Pena, C., Lei, Z., Watson, B. S., Sumner, L. W., and Vivanco, J. M. (2008). Root-microbe communication through protein secretion. J. Biol. Chem. 283, 25247-25255.

Delmotte, N., Ahrens, C. H., Knief, C., Qeli, E., Koch, M., Fischer, H.-M., et al. (2010). An integrated proteomics and transcriptomics reference data set provides new insights into the Bradyrhizobium japonicum bacteroid metabolism in soybean root nodules. Proteomics 10, 1391-1400.

Delmotte, N., Knief, C., Chaffron, S., Innerebner, G., Roschitzki, B., Schlapbach, R., et al. (2009). Community proteogenomics reveals insights into the physiology of phyllosphere bacteria. Proc. Natl. Acad. Sci. U.S.A. 106, 16428-16433.

Deutscher, J. (2008). The mechanisms of carbon catabolite repression in bacteria. Curr. Opin. Microbiol. 11, 87-93.

Dixon, R., and Kahn, D. (2004). Genetic regulation of biological nitrogen fixation. Nat. Rev. Microbiol. 2, 621-631.

Djordjevic, M. A. (2004). Sinorhizobium meliloti metabolism in the root nodule: a proteomic perspective. Proteomics 4, 1859-1872.

Felix, G., Duran, J. D., Volko, S., and Boller, T. (1999). Plants have a sensitive perception system for the most conserved domain of bacterial flagellin. Plant J. 18, 265-276.
Frohlich, A., Gaupels, F., Sarioglu, H., Holzmeister, C., Spannagl, M., and Lindermayr, J. C. (2012). Looking deep inside: detection of low-abundance proteins in leaf extracts of Arabidopsis and phloem exudates of pumpkin. Plant physiol. 159, 902-914

Gomez-Gomez, L., and Boller, T. (2000). FLS2: an LRR receptor-like kinase involved in the perception of the bacterial elicitor flagellin in Arabidopsis. Mol. Cell 5, 1003-1011.

Gomez-Gomez, L., Felix, G., and Boller, T. (1999). A single locus determines sensitivity to bacterial flagellin in Arabidopsis thaliana. Plant J. 18, 277-284.

Gourion, B., Rossignol, M., and Vorholt, J. A. (2006). A proteomic study of Methylobacterium extorquens reveals a response regulator essential for epiphytic growth. Proc. Natl. Acad. Sci. U.S.A. 103, 13186-13191

Guerreiro, N., Redmond, J. W., Rolfe, B. G., and Djordjevic, M. A. (1997). New Rhizobium leguminosarum flavonoid-induced proteins revealed by proteome analysis of differentially displayed proteins. Mol. Plant Microbe Interact. 10, 506-516.

Gust, A. A., Biswas, R., Lenz, H. D., Rauhut, T., Ranf, S., Kemmerling, B., et al. (2007). Bacteria-derived peptidoglycans constitute pathogen-associated molecular patterns triggering innate immunity in Arabidopsis. J. Biol. Chem. 282, 32338-32348.

Hauberg, L., Schmidt, F., Scharf, C., Dorr, J., Volker, U., and ReinholdHurek, B. (2010). Proteomic characterization of a pilR regulatory mutant of Azoarcus sp. strain BH72 with the aid of gel-based and gel free approaches. Proteomics 10, 458-469.

Holzmeister, C., Frohlich, A., Sarioglu, H., Bauer, N., Durner, J., and Lindermayr, C. (2011). Proteomic analysis of defense response of wild type Arabidopsis thaliana and plants with impaired NO-homeostasis. Proteomics 11, 1664-1683.

Ishikawa, T. (1992). The ATPdependent glutathione S-conjugate export pump. Trends Biochem. Sci. 17, 463-468.

Jacobs, J. M., Babujee, L., Meng, F., Milling, A., and Allen, C. (2012). The in planta transcriptome of Ralstonia solanacearum: conserved physiological and virulence strategies during bacterial wilt of tomato. mBio 3, e00114-e00112.

Jha, G., Rajeshwari, R., and Sonti, R. V. (2007). Functional interplay between two Xanthomonas oryzae pv. oryzae secretion systems in modulating virulence on rice. Mol. Plant Microbe Interact. 20, 31-40.

Johnson, T. L., Abendroth, J., Hol, W. G., and Sandkvist, M. (2006). Type II secretion: from structure to function. FEMS Microbiol. Lett. 255, 175-186.

Jones, A. M. E., Thomas, V., Bennett, M. H., Mansfield, J., and Grant, M. (2006a). Modifications to the Arabidopsis defence proteome occur prior to significant transcriptional change in response to inoculation with Pseudomonas syringae. Plant Physiol. 142, 1603-1620.

Jones, A. M. E., Bennett, M. H., Mansfield, J. W., and Grant, M. (2006b). Analysis of the defence phosphoproteome of Arabidopsis thaliana using differential mass tagging. Proteomics 6, 4155-4165.

Jones, A. M. E., Thomas, V., Truman, B., Lilley, K., Mansfield, J., and Grant, M. (2004). Specific changes in the Arabidopsis proteome in response to bacterial challenge: differentiating basal and R-gene mediated resistance. Phytochemistry 65, 1805-1816.

Jones, J. D., and Dangl, J. L. (2006). The plant immune system. Nature 444, 323-329.

Joshi, M. V., Mann, S. G., Antelmann, H., Widdick, D. A., Fyans, J. K., Chandra, G., et al. (2010). The twin arginine protein transport pathway exports multiple virulence proteins in the plant pathogen Streptomyces scabies. Mol. Microbiol. 77, 252-271.

Kadurugamuwa, J. L., and Beveridge, T. J. (1997). Natural release of virulence factors in membrane vesicles by Pseudomonas aeruginosa and the effect of aminoglycoside antibiotics on their release. J. Antimicrob. Chemother. 40, 615-621.

Kandasamy, S., Loganathan, K., Muthuraj, R., Duraisamy, S. Seetharaman, S., Thiruvengadam, R., et al. (2009). Understanding the molecular basis of plant growth promotional effect of Pseudomonas fluorescens on rice through protein profiling. Proteome Sci. 7:47. doi: 10.1186/1477-5956-7-47

Kang, Y., Kim, J., Kim, S., Kim, H., Lim, J. Y., Kim, M., et al. (2008). Proteomic analysis of the proteins regulated by $\mathrm{HrpB}$ from the plant pathogenic bacterium Burkholderia glumae. Proteomics 8, 106-121.

Karunakaran, R., Ramachandran, V. K., Seaman, J. C., East, A. K., Mouhsine, B., Mauchline, T. H., et al. (2009). Transcriptomic analysis of Rhizobium leguminosarum biovar viciae in symbiosis with host 
plants Pisum sativum and Vicia cracca. J. Bacteriol. 191, 4002-4014.

Kazemi-Pour, N., Condemine, G., and Hugouvieux-Cotte-Pattat, N. (2004). The secretome of the plant pathogenic bacterium Erwinia chrysanthemi. Proteomics 4, 3177-3186.

Koch, M., Delmotte, N., Rehrauer, H., Vorholt, J. A., Pessi, G., and Hennecke, H. (2010). Rhizobial adaptation to hosts, a new facet in the legume root-nodule symbiosis. Mol. Plant Microbe Interact. 23, 784-790.

Kurkcuoglu, S., Piotrowski, M., and Gau, A. E. (2004). Up-regulation of pathogenesis related proteins in the apoplast of Malus domestica after application of a nonpathogenic bacterium. J. Biosci. 59, 843-848.

Lai, E. M., Shih, H. W., Wen, S. R., Cheng, M. W., Hwang, H. H., and Chiu, S. H. (2006). Proteomic analysis of Agrobacterium tumefaciens response to the vir gene inducer acetosyringone. Proteomics 6, 4130-4136.

Langlois, P., Bourassa, S., Poirier, G. G., and Beaulieu, C. (2003). Identification of Streptomyces coelicolor proteins that are differentially expressed in the presence of plant material. Appl. Environ. Microbiol. $69,1884-1889$.

Larrainzar, E., Wienkoop, S., Weckwerth, W., Ladrera, R., Arrese-Igor, C., and Esther., et al. (2007). Medicago truncatula root nodule proteome analysis reveals differential plant and bacteroid responses to drought stress. Plant Physiol. 144, 1495-1507.

Lauzier, A., Simao-Beaunoir, A. M., Bourassa, S., Poirier, G. G., Talbot, B., and Beaulieu, C. (2008). Effect of potato suberin on Streptomyces scabies proteome. Mol. Plant Pathol. 9, 753-762.

Lee, S. W., Jeong, K. S., Han, S. W., Lee, S. E., Phee, B. K., Hahn, T. R., et al. (2008). The Xanthomonas oryzae pv. oryzae PhoPQ twocomponent system is required for AvrXA21 activity, hrpG expression, and virulence. J. Bacteriol. 190, 2183-2197.

Li, D., Wang, L., Teng, S., Zhang, G., Guo, L., Mao, Q., et al. (2012). Proteomics analysis of rice proteins up-regulated in response to bacterial leaf streak disease. J. Plant Biol. 55, 316-324.

Macho, A. P., Boutrot, F., Rathjen, J. P., and Zipfel, C. (2012). Asparate oxidase plays an important role in Arabidopsis stomatal immunity. Plant Physiol. 159, 1845-1856.
Mahmood, T., Jan, A., Kakishima, M., and Komatsu, S. (2006). Proteomic analysis of bacterial-blight defence responsive proteins in rice leaf blades. Proteomics 6, 6053-6065.

Mahmood, T., Kakishima, M., and Komatsu, S. (2009). Proteome analysis of probenazol- effect in ricebacterial blight infection. Protein Pept. Lett. 16, 1041-1052.

Marrs, K. A. (1996). The functions and regulation of glutathione S-transferases in plants. Annu. Rev. Plant Physiol. Plant Mol. Biol. 47, 127-158.

Martin, G. B., Bogdanove, A. J., and Sessa, G. (2003). Understanding the functions of plant disease resistance proteins. Annu. Rev. Plant Biol. 54, 23-61.

Mashburn, L. M., and Whiteley, M. (2005). Membrane vesicles traffic signals and facilitate group activities in a prokaryote. Nature 437, 422-425.

Mastronunzio, J. E., Huang, Y., and Benson, D. R. (2009). Diminished exoproteome of Frankia spp. in culture and symbiosis. Appl. Environ. Microbiol. 75, 6721-6728.

Mathesius, U., Mulders, S., Gao, M., Teplitski, M., Caetano-Anolles, G., Rolfe, B. G., et al. (2003). Extensive and specific responses of a eukaryote to bacterial quorum-sensing signals. Proc. Natl. Acad. Sci. U.S.A. 100, 1444-1449.

Mattinen, L., Nissinen, R., Riipi, T., Kalkkinen, N., and Pirhonen, M. (2007). Host-extract induced changes in the secretome of the plant pathogenic bacterium Pectobacterium atrosepticum. Proteomics 7, 3527-3537.

McCann, H. C., and Guttman, D. S. (2008). Evolution of the type III secretion system and its effectors in plant-microbe interactions. New Phytol. 177, 33-47.

McCullen, C. A., and Binns, A. N. (2006). Agrobacterium tumefaciens and plant cell interactions and activities required for inter kingdom macromolecular transfer. Annu. Rev. Cell Dev. Biol. 22, 101-127.

Miao, L., Shou, S., Zhu, Z., Jiang, F., Zai, W., and Yang, Y. (2008). Isolation of a novel tomato Caffeoyl CoA 3-O-methyltransferase gene following infection with bacterium Ralstonia solanacearum. J. Phytopathol. 156, 588-596.

Mosher, S., Seybold, H., Rodriguez, P., Stahl, M., Davies, K. A., Dayaratne, S., et al. (2013). The tyrosinesulfated peptide receptors PSKR1 and PSY1R modify Arabidopsis immunity to biotrophic and necrotrophic pathogens in an antagonistic manner. Plant J. 73, 469-482.

Mudgett, M. B. (2005). New insights to the function of phytopathogenic bacterial type III effectors in plants. Annu. Rev. Plant Biol. 56, 509-531.

Newton, A. C., Fitt, B. D. L., Atkins, S. D., Walters, D. R., and Daniell, T. J. (2010). Pathogenesis, parasitism and mutualism in the trophic space of microbe-plant interactions. Trends Microbiol. 18, 365-373.

Nomura, M., Arunothayanan, H., Dao, T. V., Le, H. T. P., Takakazu Kaneko, T., Sato, S., et al. (2010). Differential protein profiles of Bradyrhizobium japonicum USDA110 bacteroid during soybean nodule development. Soil Sci. Plant Nutr. 56, 579-590.

Ramamoorthy, V., Raguchander, T., and Samiyappan, R. (2002) Induction of defense-related proteins in tomato roots treated with Pseudomonas fluorescens Pf1 and Fusarium oxysporum f. sp. Lycopersici. Plant Soil 239, 55-68.

Rosen, R., Sacher, A., Shechter, N., Becher, D., Buttner, K., Biran, D., et al. (2004). Two dimensional reference map of Agrobacterium tumefaciens proteins. Proteomics 4, 1061-1073.

Rosen, R., Matthysse, A. G., Becher, D. Biran, D., Yura, T., Hecker, M., et al. (2003). Proteome analysis of plantinduced proteins of Agrobacterium tumefaciens. FEMS Microbiol. Ecol. 44, 355-360.

Roux, M., Schwessinger, B., Albrecht, C., Chinchilla, D., Jones, A., Holton, N., et al. (2011). The Arabidopsis leucine-rich repeat receptor-like kinases BAK1/SERK3 and BKK1/SERK4 are required for innate immunity to hemibiotrophic and biotrophic pathogens. Plant Cell 23, 2440-2455.

Salazar, E., Diaz-Mejia, J. J., MorenoHagelsieb, G., Martinez-Batallar, G., Mora, Y., Mora, J., et al. (2010). Characterization of the NifA, RpoN regulon in Rhizobium etli in free life and in symbiosis with Phaseolus vulgaris. Appl. Environ. Microbiol. 76, 4510-4520.

Sanchez, L., Courteaux, B., Hubert, J., Kauffmann, S., Renault, J.H., Clement, C., et al. (2012). Rhamnolipids elicit defense responses and induce disease resistance against biotrophic, hemibiotrophic, and necrotrophic pathogens that require different signaling pathways in Arabidopsis and highlight a central role for salicylic acid. Plant Physiol. 160, 1630-1641.
Sarma, A. D., and Emerich, D. W. (2005). Global protein expression pattern of Bradyrhizobium japonicum bacteroids: a prelude to functional proteomics. Proteomics 5, 4170-4184.

Sarma, A. D., and Emerich, D. W. (2006). A comparative proteomic evaluation of culture grown vs nodule isolated Bradyrhizobium japonicum. Proteomics 6, 3008-3028.

Seo, Y. S., Sriariyanun, M., Wang, L., Pfeiff, J., Phetsom, J., Lin, Y., et al. (2008). A two genome microarray for the rice pathogens Xanthomonas oryzae pv. oryzae and X. oryzae pv. oryzicola and its use in the discovery of a difference in their regulation of hrp genes. BMC Microbiol. 8:99. doi: 10.1186/1471-2180-8-99

Simpson, A. J., Reinach, F. C., Arruda, P., Abreu, F. A., Acencio, M., Alvarenga, R., et al. (2000). The genome sequence of the plant pathogen Xylella fastidiosa. The Xylella fastidiosa consortium of the organization for nucleotide sequencing and analysis. Nature 406, 151-159.

Smolka, M. B., Martins, D., Winck, F. V., Santoro, C. E., Castellari, R. R., Ferrari, F., et al. (2003). Proteome analysis of the plant pathogen Xylella fastidiosa reveals major cellular and extracellular proteins and a peculiar codon bias distribution. Proteomics 3, 224-237.

Soares, M. R., Facincani, A. P., Ferreira, R. M., Moreira, L. M., Oliveira, J. C. D., Ferro, J. A., et al. (2010). Proteome of the phytopathogen Xanthomonas citri subsp. citri: a global expression profile. Proteome Sci. 8:55. doi: 10.1186/1477-59568-55

Song, W. Y., Wang, G. L., Chen, L. L., Kim, H. S., Pi, L. Y., Holsten, T., et al. (1995). A receptor kinase-like protein encoded by the rice disease resistance gene, Xa21. Science 270, 1804-1806.

Torres-Quesada, O., Oruezabal, R. I., Peregrina, A., Jofre, E., Liloret, J., Rivilla, R., et al. (2010). The Sinorhizobium meliloti RNA chaperone $\mathrm{Hfq}$ influences central carbon metabolism and the symbiotic interaction with alfalfa. BMC Microbiol. 10:71. doi: 10.1186/1471-2180-10-71

Wai, S. N., Lindmark, B., Soderblom, T., Takade, A., Westermark, M., Oscarsson, J., et al. (2003). Vesiclemediated export and assembly of pore-forming oligomers of the enterobacterial ClyA cytotoxin. Cell 115, 25-35.

Washburn, M. P., Wolters, D., and Yates, J. R. 3rd. (2001). Large-scale 
analysis of the yeast proteome by multidimensional protein identification technology. Nat. Biotechnol. $19,242-247$.

Watt, S. A., Wilke, A., Patschkowski, T., and Niehaus, K. (2005). Comprehensive analysis of the extracellular proteins from Xanthomonas campestris pv. campestris B100. Proteomics 5, 153-167.

Watt, T. F., Vucur, M., Baumgarth, B., Watt, S. A., and Niehaus, K. (2009). Low molecular weight plant extract induces metabolic changes and the secretion of extracellular enzymes, but has a negative effect on the expression of the type-III secretion system in Xanthomonas campestris pv. campestris. J. Biotechnol. 140, 59-67.

Wei, C.-F., Hsu, S.-T., Deng, W.-L., Wen, Y.-D., and Huang, H.-C. (2012). Plant innate immunity induced by flagellin suppresses the hypersensitive response in non-host plants elicited by
Pseudomonas syringae pv. averrhoi. PLOS ONE 7:e41056. doi: 10.1371/journal.pone.0041056

Wengelnik, K., Marie, C., Russel, M., and Bonas, U. (1996). Expression and localization of HrpA1, a protein of Xanthomonas campestris pv. vesicatoria essential for pathogenicity and induction of the hypersensitive reaction. J. Bacteriol. 178, 1061-1069.

Wu, H. Y., Chung, P. C., Shih, H. W., Wen, S. R., and Lai, E. M. (2008). Secretome analysis uncovers an $\mathrm{Hcp}$-family protein secreted via a type VI secretion system in Agrobacterium tumefaciens. J. Bacteriol. 190, 2841-2850.

Wu, Q., Jiang, Z., Liao, J., Chen, Z., Li, H., Mei, M., et al. (2007). Identification of genetic markers to distinguish the virulent and avirulent subspecies of Pantoea stewartii by comparative proteomics and genetic analysis. Appl. Microbiol. Biotechnol. 74 186-193.
Yamazaki, A., Hirata, H., and Tsuyumu, S. (2008). HrpG regulates type II secretory proteins in Xanthomonas axonopodis pv. citri. J. Gen. Plant Pathol. 74, 138-150.

Zhang, Z., Wu, Y., Gao, M., Zhang, J., Kong, Q., Liu, Y., et al. (2012). Disruption of PAMP-induced MAP kinase cascade by a Pseudomonas syringae effector activates plant immunity mediated by the NB-LRR protein SUMM2. Cell Host Microbe 11, 253-263.

Zou, J., Rodriguez-Zas, S., Aldea, M. Li, M., Zhu, J., Gonzalez, D. O., et al. (2005). Expression profiling soybean response to Pseudomonas syringae reveals new defense-related genes and rapid HR-specific down regulation of photosynthesis. Mol. Plant Microbe Interact. 18 1161-1174.

Conflict of Interest Statement: The authors declare that the research was conducted in the absence of any commercial or financial relationships that could be construed as a potential conflict of interest.

Received: 07 December 2012; paper pending published: 11 January 2013; accepted: 29 January 2013; published online: 15 February 2013.

Citation: Afroz A, Zahur M, Zeeshan N and Komatsu S (2013) Plant-bacterium interactions analyzed by proteomics. Front. Plant Sci. 4:21. doi: 10.3389/fpls. 2013.00021

This article was submitted to Frontiers in Plant Proteomics, a specialty of Frontiers in Plant Science.

Copyright (C) 2013 Afroz, Zahur, Zeeshan and Komatsu. This is an openaccess article distributed under the terms of the Creative Commons Attribution License, which permits use, distribution and reproduction in other forums, provided the original authors and source are credited and subject to any copyright notices concerning any third-party graphics etc. 